Portland State University

PDXScholar

Fall 1-18-2019

\title{
Stigmatization and Mental Illness: the Communication of Social Identity Prototypes through Diagnosis Labels
}

Justin Samuel Leverett

Portland State University

Follow this and additional works at: https://pdxscholar.library.pdx.edu/open_access_etds

Part of the Communication Commons

Let us know how access to this document benefits you.

\section{Recommended Citation}

Leverett, Justin Samuel, "Stigmatization and Mental Illness: the Communication of Social Identity Prototypes through Diagnosis Labels" (2019). Dissertations and Theses. Paper 4681.

https://doi.org/10.15760/etd.6565

This Thesis is brought to you for free and open access. It has been accepted for inclusion in Dissertations and Theses by an authorized administrator of PDXScholar. Please contact us if we can make this document more accessible: pdxscholar@pdx.edu. 
Stigmatization and Mental Illness:

The Communication of Social Identity Prototypes through Diagnosis Labels

by

Justin Samuel Leverett

A thesis submitted in partial fulfillment of the requirements for the degree of

Master of Science

in

Communication

Thesis Committee:

Lauren Frank, Chair

Cynthia-Lou Coleman

Jeffrey Robinson

Portland State University

2018 


\begin{abstract}
This study tested whether participants exposed to a vignette describing an individual experiencing symptoms of depression, which included only the specific diagnosis label of "depression," would report significantly less stigmatized responses than participants exposed to an otherwise identical vignette which included only the nonspecific diagnosis label "mental illness." The study is grounded in past research on stigmatization of mental illness and is informed by three theoretical frameworks, the social identity perspective, attribution theory, and labeling theory. Participants were randomly assigned to read one of the two alternate vignettes, then respond to a series of measures testing desire for social distance, negative emotion (affective reaction), beliefs about people with mental illness, and perceived dangerousness of the character in response to the vignette they viewed.

The results showed that labelling the character in the vignettes as struggling with "mental illness" did lead to greater perceived dangerousness of the character described, although labelling did not lead to more stigmatization in any of the other measures. This research demonstrated that people tend to consider a character in a vignette as less trustworthy and more of a risk based solely on the label "mental illness." The experiment also tested if people who have had a personal relationship with someone who has experienced mental illness will have less stigmatized responses to mental illness vignettes, but no significant difference was shown. Overall, the results imply that use of specific language in communication labelling an individual as experiencing a mental health condition is less stigmatizing than non-specific language and may improve chances for successful treatment-seeking and future patient outcomes.
\end{abstract}




\section{Dedication}

Dedicated to my family, for being there for me always. 


\section{Acknowledgements}

I could not have done this without a great deal of support from the Portland State University faculty and staff. My advisor Lauren Frank was a constant resource and friend, and her fellow committee members Cynthia-Lou Coleman and Jeffrey Robinson offered fantastic perspective and ideas. I have also benefitted from the solidarity and insights of my amazing cohort of fellow graduate students from 2016-2018. So many friends have been there for me since I decided to re-plant myself in the Portland area, including my buddy Mountain Barber, the Quaker Voluntary Service fellows who initially welcomed me to the Northwest, my friends at Multnomah Monthly Meeting, and my childhood friends Adam Alexander and Andrew Giritharan. The city of Portland has been a wonderful welcoming environment and an ideal home these past few years, and a great place to pursue my studies. Finally, I must mention my brother Noah Leverett, my parents Betsy Herman and Thomas Leverett, and my wife Marion Edgemeyer, who were unfailingly close, kind, and so caring throughout the entire process. 


\section{Table of Contents}

\begin{tabular}{|c|c|}
\hline \multicolumn{2}{|c|}{ ABSTRACT. . } \\
\hline \multicolumn{2}{|c|}{ DEDICATION.. } \\
\hline \multicolumn{2}{|c|}{ ACKNOWLEDGEMENTS. . } \\
\hline \multicolumn{2}{|c|}{ TABLE OF CONTENTS... } \\
\hline \multicolumn{2}{|c|}{ LIST OF TABLES... } \\
\hline \multicolumn{2}{|c|}{ LIST OF FIGURES... } \\
\hline \multicolumn{2}{|c|}{ CHAPTERS } \\
\hline $\mathrm{I}$ & 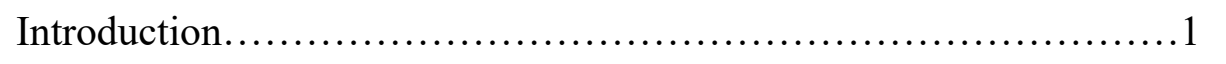 \\
\hline II & 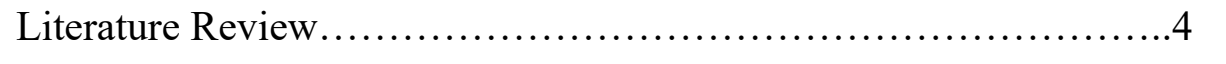 \\
\hline III & Method.... \\
\hline IV & Results...................................................... 31 \\
\hline $\mathrm{V}$ & 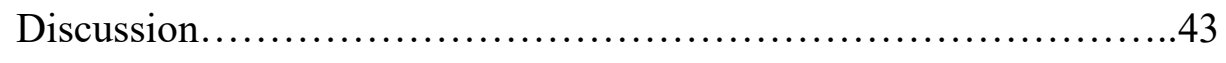 \\
\hline \multicolumn{2}{|c|}{ 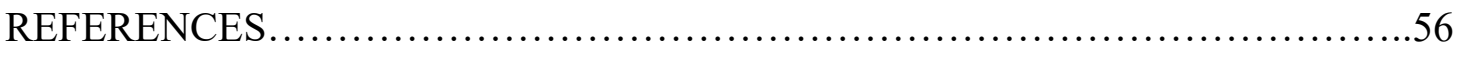 } \\
\hline \multicolumn{2}{|c|}{ 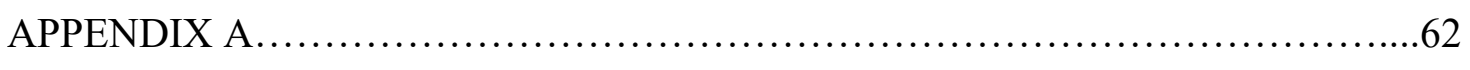 } \\
\hline \multicolumn{2}{|c|}{ APPENDIX B... } \\
\hline APPENDI & \\
\hline
\end{tabular}




\section{List of Tables}

Page

1. Pearson Correlation Among All Variables.................................32

2. Regression Analysis for Variables Predicting Stigmatized Beliefs............37

3. Regression Analysis for Variables Predicting Social Distance......................39

4. Regression Analysis for Variables Predicting Dangerousness..............40 


\section{List of Figures}

Page

1. Model of Stigmatized Reactions and Attributions....................... 11 


\section{Chapter 1 - Introduction}

Diagnosis with a mental illness is a life-altering and humbling development in the lives of those who experience it, presenting complex and persistent challenges to individuals diagnosed and to their immediate families (Corrigan, 2004; Ridge, 2012). Mental illness affects 44.7 million adults ages 18 and over in the United States (National Institute of Mental Health, 2017), and is one of the leading treatable causes of disability, morbidity, and mortality in the country (Yeh, 2017). The chances of successful long-term access, help-seeking, and adherence to mental health treatment through medication and/or therapy is subject both to income disparities and to social or cultural stigmatization related to the controversial nature of mental illness and to public attitudes toward its treatment. Income remains the strongest determinant of successful treatment for mental illness, with the American Medical Association (2010) reporting that low and middleincome countries "are home to more than $80 \%$ of the global population, but command less than $20 \%$ of the share of mental health resources" (Patel \& Prince, 2012). However, even the world's wealthiest countries like the US, Australia, Britain, Germany, and Japan remain subject to the social effects of prejudice and discrimination associated with stigmatization of mental illness.

Stigmatization of mental illness plays an important role in determining the outcome of mental health treatment (Angermeyer, 1997; Corrigan, 2004; \& Wright, 2011). Stigmatization is a social and communicative process of ostracism and groupforming closely interrelated to one's identity, personality, and social behaviors. Stigmatization has been shown to affect individuals' lasting success in social relationships and professional outcomes (Corrigan, 2004), especially for those diagnosed 
with illnesses that include symptoms of psychosis. Fewer than $40 \%$ of people prescribed anti-psychotic medication for mental illness ultimately adhere to their regimen, increasing their chance of re-hospitalization by a factor of three, and the social and communicative effect of stigmatization is a strong contributing factor to this noncompliance (Weiden \& Olfson, 1995). For people diagnosed with depression, stigmatization exacerbates reluctance to seek professional help due to fear, nervousness, embarrassment and the wish to avoid negative social responses that may result from their diagnosis (Norman, Sorrentino, Windell, \& Manchanda, 2006). When patients must return to a hostile or uninformed community after completing treatment, the success of their recovery will be limited in spite of the best effort of their doctors. Therefore, carefully-chosen language to promote less stigmatized attitudes among the wider public should greatly improve patient success and life outcomes.

Sociological, psychological, and communication research on stigmatization and mental illness has expanded in the past few decades into a fruitful research trajectory that has elaborated the cognitive processes behind labeling, discrimination, and social rejection. As research continues to improve our understanding of the communicative process of social categorization, attribution of traits, and group formation that underlies stigmatization, communicators and medical professionals are empowered to create better, more effective interventions and initiatives to counteract the negative effects of stigmatization and increase adherence to mental health care. The goal of this study was to explore the cognitive mechanisms of stigmatization by determining what reactions, attitudes, and perceived attributes are triggered most strongly by two mental illness vignettes prominently using varying diagnosis labels, including the specific label 
"depression" and the non-specific label "mental illness." First, in chapter 2, I will review past stigmatization literature and empirical research using similar experimental design and relevant constructs as well as theoretical perspectives on the topics of social identity theory, attribution theory, labeling, and group formation, in order to ground and justify the experimental design. In Chapter 3, I will provide measures and scales used in past stigmatization research to operationalize the social process of group-formation and of mental illness social identity prototyping. I will then detail participant sampling criteria, experimental design, and the procedure of the analysis of data. I will provide the structured plan of statistical testing and measures of interest to this study's research questions and hypotheses. In Chapter 4, I will report the findings, including that use of the non-specific label of "mental illness" was shown to be related significantly to greater perceived dangerousness of the character. In Chapter 5, I will provide comprehensive discussion of the study's theoretical and practical implications, limitations of this study design, and potential applications in future research.

This study was designed to inform more effective design for future health communication campaigns seeking to reduce stigmatization and to better model encouragement for help-seeking behavior among sufferers of mental illness. Long-term, this research will aid in future work to promote identification with sufferers of mental illness among the general public and medical community and increase social closeness, liking, and material support for sufferers, ultimately counteracting stigmatization of people suffering from mental illness within their friends, families, social networks and in wider communities. 


\section{Chapter 2 - Literature Review}

Stigmatization is any "discrediting mark" (Link \& Phelan, 2001) or attribute that sets an individual apart from other groups, causing stereotyping, prejudice, and discrimination, which may interfere with patients' life outcomes or with their treatment. Stigmatization can occur for many social groups based on social identity characteristics, including race, gender, sexual orientation or national origin, but is especially strong for people suffering from mental health challenges including mental illness (Goffman, 1963; Gollust \& Lynch, 2011). Stigmatization necessitates an imbalance of power between a non-stigmatized "normal" in-group and a stigmatized out-group, and usually includes the co-occurrence of five components: labeling, stereotyping, separation, status loss, and discrimination (Link \& Phelan, 2001). Stigmatization can have a significant effect on the lives of those marked by it and can have a profound effect on individuals' future earning and career prospects, chances for securing housing, criminal involvement, and quality of life (Corrigan, 2004; Scheff, 1966).

Mental illness refers to a wide range of psychological and psychiatric illnesses and afflictions, including depression, anxiety disorder, obsessive compulsive disorder, attention deficit disorder, bipolar disorder, dementia, and psychotic disorders such as schizophrenia. In their meta-analysis of 144 studies of stigmatization and mental illness between 1980 and 2011, Clement, Schauman, Graham, Maggioni, Evans-Lacko, Bezberodovs, Morgan, Rusch, Brown, \& Thornicroft (2015) assessed the relationship of stigma to likelihood of successful continued treatment. In Europe and the United States, $52-74 \%$ of people with mental illnesses do not receive treatment, especially among people with low yearly income (Clement et al., 2015). Their meta-analysis showed that 
stigma was the fourth highest-ranked barrier to help-seeking among those they identified, with disclosure concerns as the highest ranked stigmatized barrier. Stigmatization is an especially powerful barrier to people with mental illness seeking and receiving effective treatment, notably among males, younger people, and people in military or medical professions (Clement et al., 2015). Stigmatization yields two kinds of powerful harmdiminished self-esteem and reduced social opportunities — that in turn cause people to avoid seeking or fully participating in care, ultimately inhibiting successful treatment (Corrigan, 2004). A greater understanding of the relationship of diagnosis labeling to stigmatization would enable medical professionals to use language intentionally to mitigate these harms.

When individuals meet and share personal information about each other, they create referent understandings of one another through descriptive labels that facilitate a process of categorization that may also lead to de-personalization (Hogg \& Reid, 2006). For example, an individual may share with their acquaintance that they struggle with “depression," a specific label for a psychiatric diagnosis that leads to certain expectations about that individual's behavior and character. These expectations, based on prior attributions linked to the label, exist on the level of social and group interaction, as opposed to existing purely on the individual level. Stigmatization, as conceptualized in this study, exists above and beyond observed individual characteristics, and independently of any unique information about the face-to-face behaviors or real personality of the individual (Link \& Phelan, 2001). The label "depression" serves as a kind of cognitive shortcut for a set of behaviors and attributions characteristic of a depressed person, or a prototype of personality which may differ from the attributions 
characteristic of a person suffering more generally from "mental illness." Among others, characteristic responses to the "depression" label include the belief that it would be embarrassing and humiliating for the individual to seek professional help, the belief that other people would react negatively to them if it were known they had sought professional help, and the belief that they are likely to be responsible for their own condition and are likely to behave inappropriately or dangerously (Prins, Verhaak, Bensing, \& van der Meer, 2008).

Stigmatization entails two kinds of negative perceived norms - those held by the general public, and those held within the stigmatized groups, about people who bear the "discredited mark", which here refers to the diagnosis label. Stigmatization emphasizes the existence of a "shared social consensus or expectation that members of the stigmatized category are to be avoided or marginalized in social interaction" (Norman et al., 2008, p. 856). The social consensus and set of expectations held by others who are not members of the stigmatized category is known as public stigma, or beliefs held externally by non-stigmatized others, in contrast to deeply-held beliefs which reside internally by stigmatized individuals toward themselves (self-stigma). Public stigma is triggered in conversation by interlocutors through a process of cognitive and affective association with stigmatized labels, activating a process of personality categorization and attribution of prototypical traits.

The social identity perspective is based on the premise that people form social identity prototypes based on group membership, and that these prototypes then affect intergroup behaviors, such as conflict, cooperation, social change, and social stasis (Hogg \& Reid, 2006). The social identity perspective seeks to track how individuals internalize 
and enact group norms that govern their perceptions, feelings, attitudes and behaviors, and how this process informs how they navigate these group dynamics. Judgments about mental illness and affective reactions to the term "mental illness" collectively contribute to and form a social identity prototype (Hogg \& Reid, 2006) that may cause people to behave harshly toward people perceived as meeting the expected traits expected of generalized mental illness, through a process of stigmatization. A social identity prototype functions as a "fuzzy set” (Hogg \& Reid, 2006, p. 10) of attributes that represent wider similarities among people within the same groups and differences between groups. Social identity prototypes tend to submerge perceived variability and diversity within the relevant group and result in depersonalization of individuals, causing them to represent embodiments of the attributes of their wider group. Social identity prototypes are context-dependent, meaning that they may vary depending on unique situations, goals, and people physically or cognitively present, and exert a powerful influence both on how we perceive others and perceive ourselves in relation to wider groups (Hogg \& Reid, 2006).

Research on reactions to mental illness has shown how variations in narrative depictions of an individual experiencing mental illness symptoms may contribute to cognitively activating these social identity prototypes (Perkins \& Repper, 2013). People categorize one another into in-groups and out-groups based on the limited cues they receive about people and proceed to depersonalize people that they perceive to be in the outgroup (Martiny \& Kessler, 2014). Management of social identity requires a commitment of cognitive capacity, and those belonging to in-groups tend to show more negative affective reactions, less tendency to take the perspective of outsiders, and greater 
desire for social distance if they feel threatened by the out-group, and especially so if they highly value their membership in the in-group (Smeekes \& Verkuyten, 2013). Chung and Slater (2013), for example, have shown exposure to narratives edited to more greatly emphasize an otherwise similar character's more stigmatized trait affected the attitudes and attributions participants make about the character. By editing a film so that some participants viewed a version emphasizing the main character's stigmatized identity as a drug addict and others viewed a version emphasizing only her more socially accepted identity as a single parent, the researchers were able to show that the participants empathized with the character less and showed less social acceptance for her struggles after viewing the version of the film emphasizing her stigmatized social identity as a drug addict.

Public discrimination on the part of non-stigmatized people after individuals have been labeled has led to violent treatment, coercion, segregation, withholding help, or avoidance by the non-stigmatized population (Corrigan, 2004) through public stigma. Labeling theory relates public stigma, the occurrence of labeled people becoming discredited in the eyes of others, to strongly-held stereotypes, prejudice and discrimination enacted externally by the public around them. Perceptions of danger related to diagnosis labels of mental illness trigger fear, a process described in labeling theory as the danger appraisal hypothesis (Corrigan, Markowitz, Rowan \& Kubian, 2003). This reaction of fear has in the past caused people with mental illness to be confined to institutions or to be subject to violence, ostracism, and coercion. However, more contemporary studies on stigmatization have shown that the public is increasingly coming to attribute mental illness symptoms to neurobiological causes, and less often to 
more fluid personality traits such as weakness or irresponsibility (Wright, 2011). This has led to a greater movement to seek medical treatment for mental illness as opposed to long-term institutionalization, on the one hand, but has also led to an increased belief that mental illness is biologically inevitable if genetically inherited, making the negative effects of diagnosis labeling all the more tenacious.

Among the most frequently cited and tenacious effects of stigma is that of peril, otherwise known as perceived dangerousness (Ahmedani, 2011). The general public perceives those suffering with mental illness to be frightening and unpredictable, and this perception is then bolstered by frequent and exaggerated depictions of people with mental illness by the mass media as abnormal and commonly violent. Stout, Villegas, \& Jennings (2004) conducted a review of 34 content analyses of news, film, television, and other mass media assessing the ways mental illness is commonly represented. They found in multiple studies they reviewed that the majority of new stories depicting an individual with mental illness emphasize the perpetration of violent crime (Stout et al., 2004). These negative and violent portrayals also appear in children's films and on television, and researchers found that characters with mental illness are denoted with terms including "crazy," "mad," and "losing your mind," and that these characters tended to threaten or frighten other characters, concluding that children "are being socialized to have stigmatizing conceptions of mental illness" (p. 553). The socialized expectation of peril is linked to a generalized connection between abnormal behavior and "mental illness" and leads to avoidance and discomfort around those known to bear the label.

When people first share initial information with each other, they offer selfdescriptive cues which trigger a cognitive process by which each person assesses a 
checklist of affective reactions, expected qualities, and other attributions. Attribution theory relates to the ways that people base their assessments of others' personalities based on limited information. In the context of mental illness, these attributions fall into two categories, causal attributions and treatment responsibility attributions (Iyengar, 1996). First, interlocutors make causal attributions related to the origin of a given stigmatized characteristic, and specifically, about which actor initially was responsible for triggering it. People may also make treatment responsibility attributions, placing the focus on the source or actor who has the means or ability to address or to alleviate the problem. These attributions then dictate the subsequent actions, including desire for distance from the stigmatized person and unwillingness to identify with them or to help (Corrigan, 2004).

The current study assesses the differences resulting from use of a non-specific label ("mental illness") in a vignette, as opposed to use of a specific label (“depression"). Corrigan (2004) observed that stigmatization occurs through a non-specific label effect, in which people "labelled mentally ill, regardless of the specific psychiatric diagnosis or level of disability, are stigmatized more severely than those with other health conditions" (p. 614). The non-specific label effect may cause people known to suffer generally from "mental illness" to suffer stigmatization to a greater extent than people with known specific labels of mental illness diagnosis. Stigmatization occurs first through cues, which may include social deficits, physical appearance, inappropriate or abnormal behavior, or symptoms associated with an illness, and proceeding to subsequent stages of stereotyping and discrimination. Others may learn of a patient's diagnosis label directly from others (a family member, doctor, or acquaintance), or by association, after witnessing a patient 
leaving a doctor's office, for example, but if they do not receive specific information about what illness the patient is suffering from and what symptoms that illness might entail, they may judge the individual more harshly by default. In part, the study was designed specifically to empirically test and confirm the non-specific label effect.

To achieve this, I designed the experiment to conform to a model of stigmatization (Figure 1) that closely follows the cognitive process of stigmatization through prototypical attributions. The model begins with initial exposure to the label, along with the description of symptoms in the vignette. Following this exposure, participants were predicted to experience several identifiable negative reactions based on the prominence of the label and the type of label used. These reactions were predicted to vary depending on the diagnosis label used. These reactions can be classified as affective reactions and as stigmatized beliefs, the most significant of which are desire for social distance and perceived dangerousness. As a whole these reactions, or attributions, constitute the social identity prototype of the individual described in the narrative. Social desirability was additionally considered in the model as a potentially confounding factor, and therefore lies separate to but intervening on the model of stigmatization (Figure 1).

Figure 1- Model of Stigmatized Reactions and Attributions

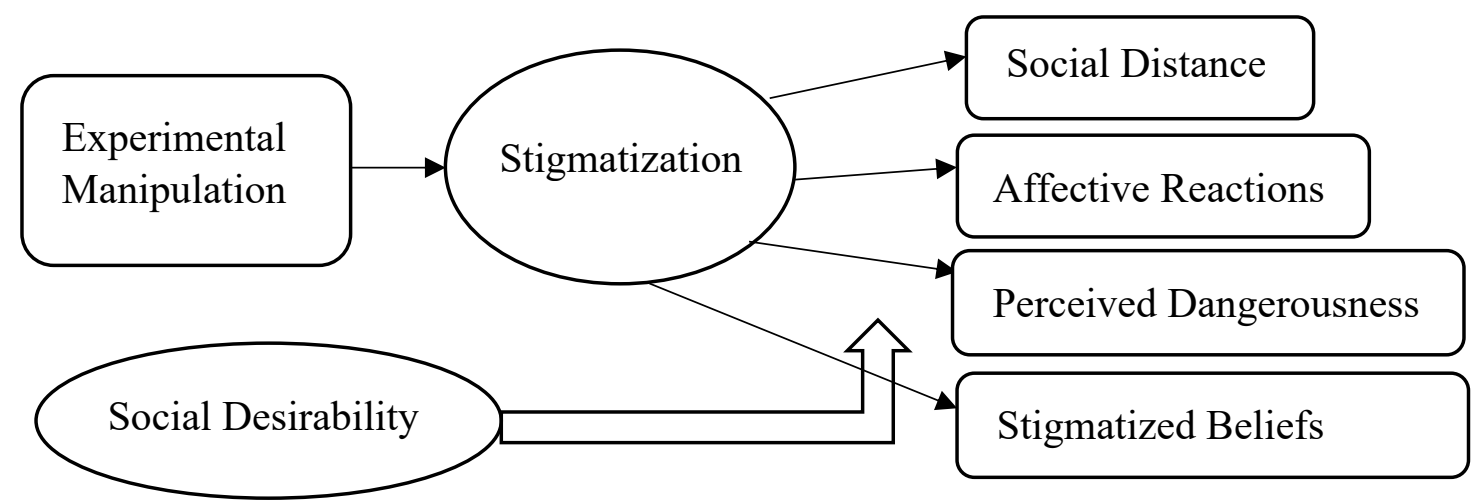


Past research has shown that in studies related to measurements of highly sensitive issues of socially appropriate affect and personality, such as this one, that participants tend to offer the response they perceive to be the most socially desirable, a phenomenon which may compromise the validity of their self-reported reactions (King \& Bruner, 2000). Social desirability bias is the tendency for individuals to present themselves, and therefore to respond to self-reported surveys, in a way that they perceive is unrealistically "socially acceptable", to such an extent that their response might contaminate the reliability of their data. This bias springs from the human psychological tendencies toward self-deception and impression management (King \& Bruner, 2000). Without methodological precautions in place to prevent it, social desirability has the potential to obscure or suppress relationships among other factors relevant to the study, or even produce artificial relationships. Therefore, a validated social desirability scale may be included in highly sensitive studies such as this one to control for the tendency to report what is socially expected.

Studies using manipulations of mental illness vignettes have shown the strongest negative, stigmatized attributions associated with mental illness to be belief in desire for social distance (Norman et al., 2008), along with other stigmatized responses including affective reactions, a number of beliefs about mental illness, and perceived dangerousness (Barney, Griffiths, Jorm, \& Christensen, 2016; Norman et al., 2008; Penn, Guynan, Daily, Spaulding, Garbin, \& Sullivan, 1994). These reactions rank among the best-known causes of how labeling leads to stereotyping, prejudice and discrimination, and quantifying and confirming these reactions will allow for a more effective effort to counteract them. The prominence and relationships of these measures illuminate and 
expand our knowledge how certain communicated messages, especially diagnosis labels, interact with stigmatized stereotyping, and can inform which messages and attitudes are best to produce greater help-seeking among people suffering from mental illness.

Desire for social distance relates to the impression that people with mental illness are unsavory or likely to do things considered by others to be rude or embarrassing, and therefore should be avoided and kept at a safe distance. Desire for social distance among the public also decreases the ease with which sufferers of mental illness feel able to approach others for help with seeking treatment or resolving their challenge. By varying the type of illness and label used referring to a character in a pre-survey vignette, Norman et al. (2008) found that illness label strongly influenced preference for greater social distance. These results were most pronounced for the schizophrenia vignette, the vignette labeled as most severe. Desire for social distance, as a measure, was closely related to but conceptually distinct from perceived dangerousness, the stereotyped belief that people with mental illness pose greater-than-normal risk of committing violent or destructive acts and therefore are not to be trusted (Angermeyer \& Matschinger, 1997; Link, Yang, Phelan, \& Collins, 2004) and similar to the previously mentioned concept of peril.

I hypothesized this pattern will remain consistent when tested between vignettes using the non-specific label and the specific diagnosis label in this experiment. I predicted that participants will desire greater social distance from a character labeled broadly as "mentally ill" due to the perceived embarrassment or awkwardness of interacting with someone whose diagnosis is not specified and the uncertainty of attributions associated with the non-specific meaning it entails. Therefore, I posed the following hypothesis. 
H1: Use of a non-specific diagnosis label of "mental illness" for a character in a mental illness vignette depicting symptoms of depression will lead to greater desire for social distance from the character, compared to a vignette depicting depression using the specific diagnosis label "depression."

Affective reaction is an immediate emotional response of study participants after exposure to the vignette which describes a feeling prior to cognitive processing, including any autonomic response to a stimulus through emotion or affect (Penn et al., 1994). These emotional responses were described and tested by Angermeyer et al. (2004) in past research as falling into one of three types: fear, pity, and anger. These emotions are derived from theory on mental illness and stigmatization and validated in past research. Affective reactions to a narrative are predicted to be more negative when the character depicted is mentally ill because of a widely accepted social identity prototype that people with mental illness are less socially adept and offer fewer rewards as acquaintances and therefore less likeable (Perkins \& Repper, 2013).

Penn et al. (1994), for example, showed that participants exposed to a vignette describing mental illness symptoms and a label of schizophrenia, and those exposed to a vignette using a description of mental illness symptoms only and no label each showed more negative affective reactions to the individual described than the group exposed to a vignette including a diagnosis label of depression, using the same affective reaction scale used in the current study. Affective reactions, here, stand in contrast to cognitive beliefs to the extent that affective reactions are less a result of subjective reasoning and rational decision-making than they are instinctive reactions that spring from past conditioning and autonomic reinforcement. Therefore, I posed the following hypothesis. 
H2: Use of a non-specific diagnosis label of "mental illness" for a character in a mental illness vignette depicting depression will lead to a more negative affective reaction to the character, compared to a vignette depicting depression using the specific diagnosis label "depression."

Perceived dangerousness, unlike social distance and affective reactions, does not function uniquely as a measure of assessment of the character in the vignette, but as a measure of broader response grounded in stigmatized reactions to the terms "depression" and "mental illness". Although perceived dangerousness has in past research been shown most significantly in response to vignettes depicting mental illnesses that include psychotic symptoms, the non-specific "mental illness" label may be more likely than the specific label "depression" to suggest that the character depicted is capable of harming himself or others (Corrigan, 2003). The term "mental illness" inspires a number of meanings, many which are relatively benign, but many others which could include potentially dangerous symptoms that could make the individual capable of physical violence or harm to themselves or others. This capacity for physical harm was predicted to elicit a fear response in study participants, which would result in less willingness to trust the character depicted in a role as a teacher or caretaker, less likelihood to recommend them for certain jobs, a desire to avoid contact with the individual, and the tendency to believe they should not be allowed to carry a hunting license or allowed access to restricted weapons. Therefore, I posed the following hypothesis.

H3: Use of a non-specific diagnosis label of "mental illness" for a character in a mental illness vignette depicting depression will lead to greater perceived 
dangerousness of the character, compared to a vignette depicting depression using the specific diagnosis label "depression."

Beliefs about mental illness refer to a series of expectations and assumptions held by the public toward people with mental illness, which relate significantly to other aspects of stigmatization of people with mental illness (Norman et al., 2008; Phelan \& Basow, 2007). For example, Norman et al. (2008) showed that beliefs about social inappropriateness, personal responsibility for illness, and reduced continuity with normal, were significantly associated with desire for greater social distance and greater belief in danger. These beliefs constitute a set of norms about people with mental illness which inform behavioral intentions toward the individual described in the mental illness vignette (Norman et al., 2008). Like perceived dangerousness, this measure of stigmatized beliefs was framed here not as a measure of unique assessment of the character in the vignette, but as a measure of broader response based in stigmatized beliefs. To test past findings, all factors of stigmatization were included in a single statistical model to test which factors predicted stigmatized beliefs, proposed a priori.

A depicted character whose illness is in remission and who has shown no sign of aberrant behavior or symptoms of their diagnosis, and simply carries the label of their mental illness diagnosis, was still likely be shunned or derided due to their mental illness, as demonstrated by Penn et al. (1994). Penn and colleagues exposed study participants to vignettes describing hypothetical cases of individuals who had just recovered from a mental illness, varying the exposure by labels used in the vignette. The results of the study showed that people who were acquainted personally with family or loved ones with mental illness, or even who had been given more information about the life context and 
living situation of individuals with mental illness, were less likely to report stigmatizing belief about people with mental illness. Therefore, in order to test and attempt to replicate this result, I posed the following additional research questions.

RQ1: Do people who have someone in their family who has suffered from mental illness have less stigmatized beliefs about people with mental illness?

RQ2: Do people who have someone in their family who has suffered from mental illness have more positive affective reactions to mental illness vignettes?

Following the procedure of Angermeyer et al. (2004), I included two demographic questions determining if participants had family members who had been treated for mental illness, and if participants had friends, co-workers or neighbors who had been treated for mental illness. This allows for a more granular understanding of the intensity and closeness with which participants were familiar with or had experience with these diagnoses, and therefore a better understanding of stigmatization and the effect of past acquaintances and personal familiarity on attitudes and opinions. I therefor posed a pair of additional research questions.

RQ3: Do people who have a friend, co-worker, or neighbor who has suffered from mental illness have less stigmatized beliefs about people with mental illness?

RQ4: Do people who have a friend, co-worker, or neighbor who has suffered from mental illness have more positive affective reactions to mental illness vignettes?

Penn et al. (1994) furthermore showed that exposure to a description of past symptomology was more stigmatizing than exposure to the label alone. Therefore, the current study included a full symptomology of depression in the experimentally manipulated mental illness vignette to sensitize participants to report attitudes revealing 
of stigmatization. Limited existing knowledge about issues of mental health among college-aged people is exacerbated by their reluctance to speak to each other about issues of mental health, depression and suicide prevention, due to the sensitivity and personal nature of the subject. Students fear that others will judge them on the basis of perceived norms that depression and mental illness are embarrassing, or that it would be rude or inappropriate to ask (Silk, Perrault, Nazione, Pace, \& Collins, 2017). Even among respondents who reported that they had past experience with individuals with mental illness, most were unable to identify the particular disorder (Penn, 1994), implying that education and public awareness about mental illness has not been adequate, and reinforcing the need for future educational and accurate health communications campaigns related to mental illness. 


\section{Chapter 3 - Method}

\section{Participants}

I conducted a Qualtrics-based experiment drawing on the undergraduate student population of a large urban university located in the Pacific Northwest, a student population unique in having a higher-than-average population of first-generation college students as well as a greater proportion of middle-aged students returning to school than most U.S. universities. I recruited student participants from undergraduate Communication classes and offered extra credit for successful completion of an experimentally-manipulated survey. To solicit responses, I distributed a digital survey link to undergraduate communication courses and offered extra credit in exchange for participation. All recruitment and survey materials were subject to Institutional Review Board (IRB) approval for ethical research practices. Participants were asked for informed consent prior to starting the experiment, were assured privacy and the right to withdraw from the experiment at any time and were provided an alternative assignment in order to still receive extra credit if they withdrew or chose not to participate. The recruitment and informed consent materials are provided in Appendices A and B. The survey was left open for 11 days. There were no follow-ups with participants after completion, apart from receiving extra credit.

Of the total participants in the experiment $(N=172)$, there were 46 who identified as males (26.7\%), 124 identified as females (72.1\%), and 2 identified as "Other." The participants were required to be older than 18 years of age $(M=26$ years, $S D=6.5)$. The ethnicity of the participants included Asian/Pacific Islander $(N=15,8.7 \%)$, Black or 
African American $(N=17,9.9 \%)$, Hispanic or Latino $(N=27,15.7 \%)$, and White/Caucasian $(N=96,55.8 \%)$.

\section{Procedure}

Participants were exposed to one of two randomly assigned two-paragraph vignettes describing symptoms and behaviors of a named male acquaintance. These vignettes were based on the vignettes used by Norman et al. (2008), with slight modifications to emphasize the appearance of labels prominently in the vignette and to eliminate mention of the term "diagnosis," for reasons of sensitivity to private medical information. All modifications are detailed below, and the full texts of these vignettes as shown to participants are included in the survey materials in Appendix C.

Mental illness vignettes and narratives are a tried and true method used to examine participants' beliefs about mental illness by causing participants to identify and react with their perspective of the characters depicted in the vignette (Chung \& Slater, 2013; Ridge, 2012). These studies have demonstrated that the use of labels and contextual information in a mental illness vignette can result in strong emotional and stigmatized responses and negative beliefs by survey participants after reading the vignette. The two vignettes depict an individual referred to as "Jamie" who has recently begun to show symptoms of depression.

The individual described in the vignettes was referred to by first name to increase identification and perspective-taking by participants. Use of a named character in narratives has been shown to increase the feeling that the character may be a person that participants could relate to or could be someone they are acquainted with in their own lives (Chung \& Slater, 2013). The two vignettes included comprised either 185 or 187 
words, differing only in the use of the term "mental illness" in place of "depression." Each experimental stimulus began with a brief sentence reading, "Imagine that you know the following about a friend, Jamie, with whom you occasionally spend time," followed by a paragraph break. The next paragraph comprised the vignette, a longer narrative describing clinical behaviors considered to be revealing of depression and Jamie's changing behavior and increasing difficulties in the workplace. The vignette was modified from Norman et al. (2008) so that the first sentence and final sentence would prominently mention each of the diagnosis labels. Specifically, the first sentence of the extended symptomology paragraph in one experimental condition reads, "Your friend seems mentally ill," and the first sentence of the extended symptomology paragraph in the other experimental condition reads, "Your friend seems depressed." This modification was made to maximize the potential for significant variation in stigmatized attitudes by participants in the subsequent questionnaire. Following this initial manipulation, all participants were exposed to the following vignette.

"Unlike before, Jamie is down and sad without being able to give a reason for his feeling low. He appears serious and worried. There is no longer anything that will make him laugh. Jamie hardly ever talks now, and if he says something, he speaks in a low tone of voice about the worries he has with regard to the future. He feels useless and has the impression that he does everything wrong. All attempts to cheer Jamie up have failed. He lost all interest in things and is not motivated to do anything. He complains often of waking up in the middle of the night and not being able to get back to sleep. By the morning, he feels exhausted and without energy. He says that he encounters difficulty in concentrating on his job. Unlike 
before, everything takes him a long time to do. He hardly manages his workload. As a consequence, Jamie has been summoned to his boss."

This paragraph detailing symptomology and abnormal behavior was followed by a final sentence after a paragraph break, for increased effect, reading either "Jamie is suffering from a mental illness," or, "Jamie is suffering from depression."

\section{Measures}

In each of the four hypotheses posed, the independent variable was based on which variation in experimental vignette (non-specific label "mental illness", or specific label “depression") was viewed by participants. In each of the research questions the independent variable was based on one of two self-reported items checking for past experience with family or with friends or co-workers who have been treated for mental illness. Following the experimental exposure, participants were asked to respond to a series of four measures of stigmatization. These measures were slightly modified versions of 9- to 12-item scales used previously by Angermeyer and Matschinger (1997), Barney et al. (2016), Norman et al. (2008), and Penn et al. (1994), who established these measures in past work as the strongest stigmatized reaction and beliefs about mental illness following exposure to mental illness vignettes and narratives. The measures included desire for social distance from the character, affective reaction to the vignette, beliefs about mental illness, and perceived dangerousness of people with mental illness. They served as the dependent variables of the experimental hypotheses and research questions. During data analysis, each was collapsed into a single composite item representing the larger multi-item scales. After these measures of stigmatization, 
participants responded to a short-form social desirability scale tested originally by Reynolds (1982). More information about each measure follows.

Social distance. In order to assess desire for social distance from the individual depicted after exposure to a mental illness vignette, Penn et al. (1994) used a seven-item scale based on a series of statements. The social distance scale captures participants' level of willingness to take the actions listed in seven statements referring directly to the character "Jamie" from the vignette. Penn et al. (1994) reported a Cronbach alpha reliability of $\alpha=.75$ for this scale. These items included, "How would you feel about being a roommate with someone like Jamie?", "How would you feel about being a worker on the same job as someone like Jamie?", "How would you feel having someone like Jamie as a neighbor?", "How would you feel about Jamie as the caretaker of your children for a couple of hours?", "How would you feel about having your children marry someone like Jamie?", "How would you feel about introducing Jamie to a single person you are friendly with?", and "How would you feel about recommending someone like Jamie for a job working for a friend of yours?" These statements are designed to assess participants' comfort level and willingness to interact closely with the character in the vignette. The wording was modified to increase relevance for a student population in the first item, from the original "How would you feel about renting a room in your home to someone like Jamie?" to "How would you feel about being a roommate with someone like Jamie?” All items were assessed with 5-point Likert-type scales $(1=$ definitely willing, 5 = definitely unwilling). In this experiment, the social distance scale showed a Cronbach alpha reliability of $\alpha=.86$. 
Affective reaction. To capture participants' self-described reactions on a spectrum of emotional and affective response to the vignettes, a ten-item semantic differential scale previously used by Penn et al. (1994) was employed to assess participants' response. The Affective Reaction Scale consists of ten adjective pairs describing emotional content (pessimistic-optimistic, tranquil-nervous, supportiveresentful, fearful-confident, empathic-angry, disgusted-sympathetic, apprehensivecomfortable, irritable-patient, relaxed-tense, and calm-nervous), with participants asked to rate each item on a 6-point scale. Penn et al. (1994) reported a Cronbach alpha reliability of $\alpha=.86$ for the scale. The scales were not numbered and were arranged in a centered display on Qualtrics with one adjective on either side of a series of six selectable locations, following detailed instructions to participants drafted as follows.

'Each question below has a pair of opposite impressions or emotions (such as "optimistic" vs. "pessimistic"). Please mark one of the six locations, on the scale, closest to the term that you feel most closely matches the impression or emotion you'd experience in this interaction. For example, if you'd feel very optimistic about interacting with Jamie, please select a position on the scale very close to the term "optimistic." Please make your decisions quickly, based on your truest and most authentic gut feeling.'

In this experiment, the affective reaction scale showed a Cronbach alpha reliability of $\alpha=$ .87.

Beliefs about mental illness. Participants' stigmatized beliefs about mental illness were measured using a reduced form of a more comprehensive scale developed initially in a stigmatization study by Angermeyer and Matschinger (1997) and adapted 
and validated by Norman et al. (2008). Respondents were asked to indicate their level of agreement $(1=$ strongly disagree to $6=$ strongly agree $)$ with ten statements about mental illness related to personal responsibility, continuity with normal, and social inappropriateness. Norman et al. (2008) reported a Cronbach alpha reliability at $\alpha=$.74.83 for beliefs about mental illness.

The items included in this study, comprising ten statements, were aggregated into one measure. Statements were, "Whether or not you get a mental illness is a matter of will power and self-discipline," "Mental illness comes about when someone stops making an effort to deal with the challenges of life," "People develop mental illness because they are easily stressed," and "Mental illness results from a failure of self-control," "Most of us from time to time show symptoms of mental illness," "Normal people can have some of the symptoms of mental illness," "Given extreme circumstances, many of us could show signs of mental illness," "People with mental illness often say rude and upsetting things," "You can often be embarrassed by what someone with mental illness says or does," and "People with mental illness are often inappropriate when interacting with others." In this experiment, the beliefs about mental illness scale showed an overall Cronbach alpha reliability of $\alpha=.78$.

Perceived dangerousness. Perceived dangerousness was measured via the dangerousness scale (Penn et al., 1994). Respondents were asked to indicate their level of agreement ( 1 = strongly disagree, 6 = strongly agree $)$ with nine statements including, "If a group of people with mental illness lived nearby, I would not allow my children to go to the movie theater alone," "If someone with mental illness applied for a teaching position at a grade school and was qualified for the job, I would recommend hiring him/her," 
"One important thing about people with mental illness is that you cannot tell what they will do from one minute to the next," "If I know a person has been diagnosed with mental illness, I will be less likely to trust them," "The main purpose of mental hospitals should be to protect people from mentally ill people," "If someone with a mental illness lived nearby, I would not hesitate to allow young children under my care on the sidewalk," "Although some people with mental illness may seem all right, it is dangerous to forget for a moment that they are mentally ill," and "There should be a law forbidding people with mental illness the right to obtain a hunting license.” Of note, Penn et al. (1994) tested this dangerousness scale and reported a Cronbach alpha reliability coefficient at $\alpha$ $=.78$ for perceived dangerousness. An additional item, “There should be a law forbidding people with mental illness the right to purchase a gun" was drafted and added to the scale for contemporary relevance. For participants exposed to the vignette using the term "depression" in place of "mental illness", the statements in this scale were also altered to use the term "depression", to match the procedure of Penn et al. (1994). In this experiment, the perceived dangerousness scale showed a Cronbach alpha reliability of $\alpha$ $=.75$.

Social desirability. Social desirability was measured using the short form M-C Form C of the Marlowe-Crowne social desirability index (Reynolds, 1982). This 13-item measure was based on Reynolds' work to produce a series of effective short forms of the extended scale. $\mathrm{M}-\mathrm{C}$ form $\mathrm{C}$ was chosen because it has shown relatively high reliability while remaining very parsimonious, including only 13 statements. Respondents were asked to indicate their level of agreement $(1=$ strongly disagree, $6=$ strongly agree $)$ with a series of statements including, "It is sometimes hard to go on with my work when I 
am not encouraged," "I sometimes feel resentful when I don't get my way," "On a few occasions, I have given up doing something because I thought too little of my ability," "There have been times when I felt like rebelling against people in authority even though I knew they were right," "No matter who I'm talking to, I'm always a good listener," "There have been occasions when I've taken advantage of someone," "I'm always willing to admit when I've made a mistake," "I sometimes try to get even rather than forgive and forget," "I am always courteous, even to people who are disagreeable," "I have never been irked when people expressed ideas quite different from my own," "There have been times when I was quite jealous of the good fortunes of others," "I am sometimes irritated by people who ask favors of me," and "I have never deliberately said something that hurt someone's feelings.” Of note, Reynolds (1982) tested this reduced form of the extended scale and showed a reliability index of .76, the highest reliability among short forms with a comparable number of items, relative to the longer scale. In this experiment, the social desirability scale showed a Cronbach alpha reliability of $\alpha$ $=.76$.

The results of the social desirability measure were used to check all participant data for individuals with an abnormally high tendency to self-report highly socially desirable responses, and those participants were then considered for exclusion from the central analyses. This resulted in two datasets, one full sample which included all participants and one restricted sample excluding the participants with the most highly socially desirable responses. In all other measures, there was no significant difference in Cronbach alpha reliability between the full sample and the restricted sample, therefore, for increased parsimony, I only report alpha results from the entire sample. In results 
reporting, the social desirability scale became no longer valid in the restricted sample and was therefore not included alongside other results. Regression models only include social desirability as a predictor if conducted on the full data set prior to excluding these participants.

Manipulation checks. Participants also responded to a manipulation check to confirm they were cognizant of the crucial difference in diagnosis labels. The manipulation check asked, "Which of the following statements best applies to your friend Jamie?", and participants responded with a choice of four responses, "Jamie is experiencing nothing abnormal, "Jamie is experiencing depression," "Jamie is experiencing a mental illness," or "I prefer not to respond." The manipulation check was placed near the end of the survey, just before demographic items, and served as an initial test for response quality and a measure of participant impressions of the diagnosis labeling based on the vignettes, during data analysis.

Demographics. Participants responded to five demographic survey questions asking for gender, age, ethnicity, past experience personally with a family member who has experienced mental illness, and past experience personally with a friend, co-worker, or neighbor who has experienced mental illness. Although demographic information was not used in any of the central tests, the information was considered useful in determining background information of participants and the extent to which this study may be considered representative of the wider population. The questions about past experience with others experiencing mental illness were posed as a pair of three-item nominal questions ("Do you have a family member who has been or is undergoing psychiatric treatment?", and "Do you know someone within your circle of friends, among your co- 
workers, or in your neighborhood who has been or is undergoing psychiatric treatments?") with three response options, ("Yes", "No", and "I prefer not to answer.") These nominal items, replicated from Angermeyer et al. (2004), served as independent variables for the four research questions listed above, and were included to confirm if past relationships with family, friends or co-workers would reduce the effects of stigmatization, as predicted in previous literature. Participants were finally asked an open-ended response question, "Do you have any additional thoughts or reactions you would like to share?"

\section{Analysis}

Each scale used in this study was copied word-for-word from past research, with minimal modifications to increase relevance for the college population. Where necessary, items reverse-coded for use in the survey were adjusted during data cleaning to ensure consistency across the scale before running statistical tests. Each scale was tested for reliability, then collapsed into a single, composite measure to aggregate the data for use in statistical tests. The analysis concerned the relationship of three independent variables (use of specific vs. non-specific mental illness labels in a pre-survey vignette, past relationship with a family member who has suffered from mental illness, and past relationship with a friend or co-worker who has suffered from mental illness) and isolated their relationship to the previously mentioned four dependent measures of stigmatization (desire for social distance, affective reactions, beliefs about mental illness, perceived dangerousness). Significance was set a priori for all tests at .05, two-tailed.

Social desirability has been shown to potentially compromise self-reported results in past research on self-reported attitudes toward sensitive and personal issues like 
stigmatization and mental illness. Therefore, all hypotheses and research questions were initially tested on the whole group of participants $(\mathrm{N}=172)$ once before excluding all participants who reported a mean social desirability of higher than $4.5(\mathrm{~N}=13)$. The hypotheses and research questions were then re-tested without those participants identified as showing the highest social desirability and checked for any differences. Any regression models tested which included social desirability as a variable included it only when conducted on the total group of participants. Social desirability was not used as a variable after exclusion of those participants with highest social desirability, to maintain viable reliability of the measure. 


\section{Chapter 4 - Results}

The survey yielded an initial total of 178 participants. First, any participants with missing data or responses that consistently did not vary across measures, such as participants who responded invariably and consistently to every item in a scale with $3 \mathrm{~s}$ or $4 \mathrm{~s}$, for example, in one or more scales (comprising 10-13 single items), were excluded to reduce response bias and contamination of data. After excluding participants with missing data in one or more entire scales and those whose responses did not vary $(N=3)$ in one or more entire scales, the total was reduced to 175 participants.

A timer was set using Qualtrics to record the length of time each participant viewed the initial experimental vignette, and a minimum of 3 seconds was set a priori as a baseline for inclusion in any final statistical tests. Participants were excluded who viewed the experimental vignette for less than 3 seconds $(N=3)$, and the total participants in the final analysis was reduced to $N=172$ participants. Of this final analytic sample, 87 participants viewed the "depression" condition, and 85 participants viewed the "mental illness" condition.

The primary independent variable, used in Hypotheses 1-3, was the manipulation of wording used in the mental illness vignette. Each hypothesis isolated the effect of this one manipulation on a single dependent variable, starting with desire for social distance in $\mathrm{H} 1$, followed by affective reactions in $\mathrm{H} 2$, and finally perceived dangerousness in $\mathrm{H} 3$. A significant difference would demonstrate that participants who read a vignette using the term "mental illness" tend to react differently on that particular dependent measure than those who read a vignette using the term "depression." Independent samples $t$-tests were used to determine the significance of these relationships. 
First, an analysis of all correlations between the factors included in the study was conducted on the overall sample of every participant, regardless of whether they viewed the "depression" vignette or the "mental illness" vignette. The results of this analysis of correlations is below (Table 1).

Table 1: Correlations

Pearson Correlations Among all Variables

Social Social Affective $\quad$ Perceived

Variable M SD Desirability Distance Reaction Beliefs Dangerousness

\begin{tabular}{llll}
\hline Social $\quad 3.59$ & 0.65 & 1
\end{tabular}

Desirability

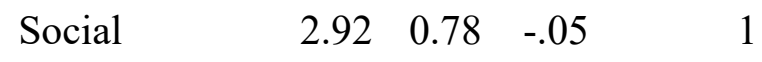

Distance

Affective $\quad 2.68 \quad 0.79 \quad-.26^{* *} \quad .41^{* *} \quad 1$

Reactions

\begin{tabular}{|c|c|c|c|c|c|c|c|}
\hline Beliefs & 2.92 & 0.49 & -.13 & $.30^{* *}$ & $.27^{* *}$ & 1 & \\
\hline Dangerousness & 2.50 & 0.73 & -.04 & $.33^{* *}$ & $.28^{* *}$ & $.53^{* *}$ & 1 \\
\hline
\end{tabular}

The results of the manipulation check showed a prevailing understanding among all participants that the character was likely experiencing depression. Participants were asked whether Jamie, the character in the vignette, was experiencing either "nothing abnormal”, “depression", "mental illness", or if they preferred not to answer. The majority of participants $(\mathrm{N}=120,73.1 \%)$ believed Jamie was experiencing depression, 
compared to a minority $(\mathrm{N}=29,17 \%)$ who agreed that Jamie was experiencing mental illness. A small group of participants $(\mathrm{N}=17,9.9 \%)$ said they preferred not to answer, and very few $(\mathrm{N}=5,2.9 \%)$ said he was experiencing nothing abnormal. Participants understood that the vignette described an individual suffering from depression, regardless of labelling. A chi-square test was used to determine whether there was a significant difference between participants who viewed the "depression" condition and those who viewed the "mental illness" condition in reporting that Jamie was experiencing “depression" or "a mental illness." This difference was not statistically significant, $\chi^{2}(1)$ $=.60, \mathrm{p}=.90 .71 .8 \%$ of those who viewed the "depression" condition reported Jamie as experiencing depression, whereas $68.6 \%$ of those who viewed the "mental illness" condition reported Jamie as experiencing depression.

Hypothesis 1 predicted that participants who viewed the vignette emphasizing the term "depression" would feel less desire for social distance from the character depicted, compared to the participants who viewed a vignette emphasizing the non-specific term “mental illness." The results of a two-tailed independent samples $t$-test did not support this hypothesis, $(t(170)=0.056, p=.96)$. Participants rated a similar desire for social distance from the character in the vignette using the term "depression" $(M=2.92, S D=$ $0.81)$ as from the character in the vignette using the term "mental illness" $(M=2.91, S D$ $=0.76$ ). After excluding the 13 participants with the highest responses on the social desirability scale and conducting the $t$ test again, this hypothesis was again not supported $(t(157)=0.041, p=.97)$

Next, Hypothesis 2 predicted that participants who viewed the vignette emphasizing the term "depression" would feel a more positive affective reaction to the 
character depicted, compared to the participants who viewed a vignette emphasizing the non-specific term "mental illness." Like Hypothesis 1, the results of a two-tailed independent samples $t$-test did not support this hypothesis, $(t(168)=0.152, p=.91)$. Participants rated a similar affective reaction to the character in the vignette using the term "depression" $(M=2.69, S D=0.81)$ as to the character in the vignette using the term "mental illness" $(M=2.67, S D=0.82)$. After excluding the 13 participants with the highest responses on the social desirability scale and conducting the $t$-test again, this hypothesis was again not supported $(t(155)=0.264, p=.91)$.

Finally, Hypothesis 3 predicted that participants who viewed the vignette emphasizing the term "depression" would perceive the character depicted as less dangerous compared to the participants who viewed a vignette emphasizing the nonspecific term "mental illness." In this case, the results of a two-tailed independent samples $t$-test supported the hypothesis, $(t(170)=-2.82, p=.005)$. Participants perceived the character in the vignette using the term "depression" $(M=2.34, S D=0.73)$ as significantly less dangerous than the character depicted in the vignette using the term "mental illness" $(M=2.65, S D=0.71)$. After excluding the 13 participants with the highest responses on the social desirability scale and conducting the $t$-test again, this hypothesis was again supported $(t(157)=-2.56, p=.01)$. Participants perceived the character in the vignette using the term "depression" $(M=2.36, S D=0.72)$ as significantly less dangerous than the character depicted in the vignette using the term "mental illness" $(M=2.65, S D=0.73)$.

The independent variables used in Research Questions 1-4 was one of two demographic items asking if participants had a past relationship with someone who had 
been treated for mental illness. Each research question tested the effect of this relationship on one of two dependent variables, affective reactions or stigmatized beliefs. A significant difference would demonstrate that participants who had a family member, or who had a friend or co-worker who had been treated for mental illness, would react differently on that particular dependent measure than those who hadn't. Independent samples $t$-tests were used to determine the significance of these relationships.

Research Question 1 asked whether participants who had someone in their family who had experienced mental illness would report a more positive affective reaction to people with mental illness compared to participants who did not have someone in their family who had experienced mental illness. The results of a two-tailed independent samples $t$-test showed there was no difference in affective reaction to the vignette based on past experience with a family member who had experienced mental illness, $(t(159)=$ $0.175, p=.86$ ). Participants rated a similar affective reaction to people with mental illness whether they had someone in their family who had been treated for mental illness $(M=2.65, S D=0.90)$ as those who did not have someone in their family who had been treated for mental illness $(M=2.67, S D=0.66)$.

Similarly, Research Question 2 asked whether participants who had someone in their family who had experienced mental illness would report less stigmatized beliefs compared to participants who did not have someone in their family who had experienced mental illness. As in Research Question 1, the results of a two-tailed independent samples $t$-test did not show any difference in stigmatized beliefs, $(t(161)=-1.46, p=.15)$. Participants did not hold less stigmatized beliefs if they had someone in their family who 
had been treated for mental illness $(M=2.85, S D=0.48)$ than those who did not have someone in their family who had been treated for mental illness $(M=2.96, S D=0.51)$.

Next, Research Question 3 asked whether participants who had a friend or coworker who had experienced mental illness would report more positive affective reactions compared to participants who did not have a friend or co-worker who had experienced mental illness. The results of a two-tailed independent samples $t$-test showed no difference in affective reaction based on past experience with a friend or co-worker who had been treated from mental illness, $(t(157)=.175, p=.86)$. Participants did not report more positive affective reaction to people with mental illness if they had a friend or co-worker who had been treated for mental illness $(M=2.65, S D=0.87)$ than those who did not have a friend or co-worker who had been treated for mental illness $(M=$ $2.63, S D=0.64)$

In addition, Research Question 4 asked whether participants who had a friend or co-worker who had experienced mental illness would report less stigmatized beliefs compared to participants who did not have a friend or co-worker who had experienced mental illness. The results of a two-tailed independent samples $t$ test rejected this hypothesis, $(t(159)=-0.422, p=.67)$. Participants reported the same levels of stigmatized beliefs toward people with mental illness if they had someone in their family who had been treated for mental illness $(M=2.88, S D=0.49)$ as those who did not have someone in their family who had been treated for mental illness $(M=2.91, S D=0.45)$.

Finally, as a follow up to these hypotheses and research questions, OLS regression was used in a series of follow-up tests for the purpose of checking predictor relationships as well as for post hoc observations. All results report unweighted betas. 
The initial regression model, included below in Table 2, used a linear model including stigmatized beliefs about mental illness as a dependent variable and tested for the predicting effects of the independent variables, including social desirability, social distance, affective reactions, and perceived dangerousness. This regression was proposed a priori to identify if other aspects of stigmatization included in this study were significantly related to the measure of stigmatized beliefs, with the intent to more clearly describe and understand the relationships between factors of stigmatization in the study. The results of the analysis are included below (Table 2).

Table 2- Regression Analysis for Variables Predicting Stigmatized Beliefs

\begin{tabular}{|c|c|c|c|c|}
\hline \multirow[b]{2}{*}{ Variable } & \multicolumn{2}{|c|}{$\begin{array}{l}\text { Full Sample } \\
(N=172)\end{array}$} & \multicolumn{2}{|c|}{$\begin{array}{l}\text { Excluding Highest Social } \\
\text { Desirability }(N=159)\end{array}$} \\
\hline & $\beta$ & $p$ & $\beta$ & $p$ \\
\hline Social Desirability & -0.01 & .15 & & \\
\hline Social Distance & 0.11 & .13 & 0.09 & .23 \\
\hline Affective Reaction & 0.07 & .35 & 0.11 & .14 \\
\hline Perceived Dangerousness & 0.48 & $.00 * *$ & 0.47 & $.00 * *$ \\
\hline$R^{2}$ & & $.32 * *$ & & $.31 * *$ \\
\hline$F$ & & 19.17 & & 22.79 \\
\hline
\end{tabular}

The results of this regression echoed the findings in Hypotheses 1, 2, and 3, showing the only significant relationship to stigmatized beliefs about mental illness was to perceived dangerousness of people with mental illness. The model showed no 
significant relationships between social desirability, social distance, or affective reactions and stigmatized beliefs. Although stigmatized beliefs about mental illness were not found to be related significantly to the experimental variation of labelling in the narrative, these beliefs about mental illness were in fact shown to be predicted by whether or not participants would perceive people with mental illness to be dangerous.

\section{Post-hoc Analyses}

For purposes of post hoc analysis, participants were asked to consider if they believed depression to be a mental illness. Participants rated their agreement with the statement "I consider depression to be a mental illness" on a six-point Likert scale. This question was included to determine whether participants felt that the concepts were mutually exclusive, or if they felt that the diagnosis label of "depression" was one which fell under a broader category of illnesses that may be named "mental illness." Participants predominantly perceived depression to be a mental illness on a six-point Likert scale (M $=4.80, \mathrm{SD}=1.12$ ). This aligns with the results of the manipulation check, in which more than $70 \%$ of participants agreed that Jamie was suffering from depression, regardless of whether labelled in this way or labelled as "mentally ill”. Given that participants overwhelmingly believe depression to be a mental illness, the observed variance in responses between the two groups further reinforces the non-specific label effect.

Two additional regression analyses were conducted to investigate a number of relationships to other variables were detected in follow-up analyses. The first regression used social distance as the dependent variable and the second regression used perceived dangerousness as the dependent variable. In the first regression, social desirability, affective reactions, stigmatized beliefs, and perceived dangerousness were included as 
predictors. This regression was meant to confirm the correlation between affective reaction and social distance, as noted among the correlations between all factors, and determine if affective reaction can predict desire for social distance. Only unweighted betas are reported. The results of this follow-up analysis are included below (Table 3). Table 3- Regression Analysis for Variables Predicting Social Distance

\begin{tabular}{|c|c|c|c|c|}
\hline \multirow[b]{3}{*}{ Variable } & \multicolumn{2}{|c|}{ Full Sample $(N=172)$} & \multirow{2}{*}{\multicolumn{2}{|c|}{$\begin{array}{l}\text { Excluding Highest Social } \\
\text { Desirability }(N=159)\end{array}$}} \\
\hline & & & & \\
\hline & $\bar{\beta}$ & $p$ & $\beta$ & $p$ \\
\hline Social Desirability & 0.07 & .36 & & \\
\hline Affective Reaction & 0.35 & $.00 * *$ & 0.34 & $.00 * *$ \\
\hline Stigmatized Beliefs & 0.12 & .14 & 0.10 & .23 \\
\hline Perceived Dangerousness & 0.18 & $.03 *$ & 0.18 & $.03 *$ \\
\hline$R^{2}$ & & $.24 * *$ & & $.24 * *$ \\
\hline$F$ & & 12.68 & & 15.67 \\
\hline
\end{tabular}

Social distance, while not significantly related to the experimental manipulation in H1, merited a follow-up regression analysis to clarify if there were other relationships not identified. This regression did show a significant relationship between negative affective reactions in response to the vignette and desire for social distance from the person depicted, as well as a significant relationship between perceived dangerousness and desire for social distance. While the use of the non-specific label may not have been 
related to social distance, as predicted, negative affective reactions to the character in the vignette did predict desire for social distance in this regression model.

In the next model, the dependent variables related to past relationships used in RQ1, RQ2, RQ3, and RQ4, were included in a regression model (Table 4) investigating whether prior family relationship or prior friend or co-worker relationship along with all other variables may relate to perceived dangerousness. Only unweighted betas are reported. The results of this follow-up analysis are included below (Table 4).

Table 4- Regression Analysis for Variables Predicting Dangerousness

\begin{tabular}{|c|c|c|c|c|}
\hline \multirow[b]{3}{*}{ Variable } & \multicolumn{2}{|c|}{ Full Sample $(N=172)$} & \multirow{2}{*}{\multicolumn{2}{|c|}{$\begin{array}{c}\text { Excluding Highest Social } \\
\text { Desirability }(N=159)\end{array}$}} \\
\hline & & & & \\
\hline & $\beta$ & $p$ & $\beta$ & $p$ \\
\hline Social Desirability & 0.02 & .81 & & \\
\hline Prior Family Relationship & 0.10 & .16 & 0.06 & .44 \\
\hline Prior Friends Relationship & 0.16 & $.03 *$ & 0.19 & $.01 *$ \\
\hline Social Distance & 0.07 & $.02 *$ & 0.05 & $.02 *$ \\
\hline Affective Reaction & 0.07 & .34 & 0.18 & .47 \\
\hline Stigmatized Beliefs & 0.42 & $.00 * *$ & 0.42 & $.00 * *$ \\
\hline$R^{2}$ & & $.36^{* *}$ & & $.35^{* *}$ \\
\hline$F$ & & 14.89 & & 16.22 \\
\hline
\end{tabular}


This regression resulted in a larger $\mathrm{R}^{2}$, showing that the two variables relating whether participants have had a relationship with a friend, coworker, or neighbor experiencing mental illness increased the overall variance of perceived dangerousness accounted for by the model. The model showed a significant relationship of prior friendly relationship to perceived dangerousness of the character in the vignette. The coefficient of this relationship became more pronounced when people reporting the highest social desirability were excluded from the analysis. The results of this regression also showed a weak relationship between social distance and perceived dangerousness and a strong relationship between stigmatized beliefs and perceived dangerousness, when controlling for past relationships with a family member or with friends or co-workers experiencing mental illness.

Finally, a pair of exploratory post-hoc independent samples $t$-tests were conducted based on the results above, with perceived dangerousness as the independent variable and existence of a prior relationship with a family member experiencing mental illness as the independent variable. Although hese $t$-tests were excluded as a priori research questions for reasons of parsimony, following the analysis they were determined to be of interest. Interestingly, these $t$-tests showed that the relationship between existence of prior relationship with a family member experiencing mental illness and perceived dangerousness was contingent upon whether or not the participants with the highest social desirability scores were included in the sample.

In the sample including the 13 individuals with the highest social desirability scores, the relationship between existence of a prior relationship with a family member with mental illness to perceived dangerousness of people with mental illness was 
significant $(t(161)=.248, p=.029)$. However, in the sample with these 13 individuals excluded, this same relationship was not significant $(t(149)=-.1797, p=.074)$. These tests were conducted post hoc, and not formulated prior to data-gathering, and therefore they can only be considered as interesting observations of existing data and cannot be taken as evidence of a demonstrated causal relation. 


\section{Chapter 5 - Discussion}

This study compared the difference in stigmatized participant reactions between two otherwise identical vignettes which used two different diagnosis labels, "depression" and "mental illness." These stigmatized participant reactions included measures of social distance, affective reactions, stigmatized beliefs, and perceived dangerousness. The results showed that contrary to the predictions in $\mathrm{H} 1$ and $\mathrm{H} 2$, neither participants' desire for social distance from the character in the vignette nor participants' affective reaction to the character in the vignette significantly differed between groups after being exposed to different labeling. Past research pointed to social distance as ranking among the strongest aspects of stigmatization, and increased social distance was therefore hypothesized as a potential result of the experimental change in diagnosis labeling. This prediction was not observed in this experiment, implying that a variation of diagnosis labels may not be expected to result in desire for greater social distance from the character in the vignette, nor in a change in affective response.

These results, while relevant to the attributions caused by a change in diagnosis labels, cannot be said prove that social distance or affective reaction are not relevant aspects of stigmatization. On the contrary, results showed social distance is significantly correlated to multiple other important factors, including both affective reactions and perceived dangerousness (Table 1). The primary hypotheses simply showed these factors to not have been related to a variation in specific and non-specific labelling as focused on in the scope of this course research. Social distance and affective reactions may be concluded to be less consequential for future studies of mental health labelling, but their 
strong correlation with other factors of stigmatizations in follow-up analyses nonetheless point to high potential for further research.

The results did show that participants who read that the character was suffering from mental illness perceived him to be more dangerous than those who read that he was suffering from depression, as predicted in H3. This finding entails that on average, participants who read the vignette describing Jamie as "mentally ill" were more likely to attribute to him the characteristics of a dangerous individual to be avoided and mistrusted. It follows that individuals bearing the label of "depressed" or "mentally ill" would have reason to feel reluctant to share their condition with friends or health professionals, for fear of the repercussions of these stereotyped perceptions. The construct "perceived dangerousness" included willingness to trust the person described, likelihood to recommend him for certain jobs, reluctance to leave children alone or unattended if Jamie was known to live in the neighborhood, and a belief that certain legal protections should not be extended to him... a set of beliefs typically contributing to behaviors of social stigmatization and ostracism. These findings support the existence of stigmatized attributions activated singularly by the label of "mental illness", attributions especially salient in light of the modern discourse on mental illness policy and treatment following crisis events like mass shootings and terrorism as portrayed in mass media, which may exacerbate this stereotype of danger.

Participants overwhelmingly recognized based on the vignettes that the symptoms described were characteristic of depression, but nonetheless perceived the character labelled with "mental illness" to be more dangerous. Although participants predominantly perceived depression to be a mental illness on a six-point Likert scale (M 
$=4.80, \mathrm{SD}=1.12)$, the label "mental illness" caused a wider and more severe range of stigmatized attributions, probably due to the label "mental illness" implying a range of other possible illnesses which may include other more severe symptoms and potentially dangerous behaviors, such as psychotic disorders or mood disorders which may include delusions or unpredictable behavior. This provides strong support for the danger appraisal hypothesis described in labeling theory (Corrigan, Markowitz, Rowan, \& Kubian, 2003), which asserts that more severe diagnosis labels are associated with danger, triggering a feeling of fear that results in a greater desire for distance and less contact with the stigmatized individual. This result also provides strong support for the non-specific label effect, which asserted that people labelled mentally ill are stigmatized more severely than those with other health conditions, regardless of level of disability or their specific diagnosis.

These results are especially interesting given that so many participants identified that Jamie was experiencing depression. It follows that the prototyping effect of nonspecific labelling alone caused participants to believe that people suffering from mental illness are more dangerous even when they understand that the mental illness being described is actually depression. Furthermore, if the character were labeled specifically as "depressed" alone, with no mention of the more stigmatized label "mental illness", they would not be as stigmatized. The results imply that use of a broader, less specific label carries independent meanings of its own, which independently exacerbate the stigmatizing social effects already suffered by an individual experiencing depression. It follows that the term "mental illness" should be used by health professionals and by the 
wider public with extreme care, and avoided if at all possible it a term more accurately describing the diagnosis that best fits the symptoms is made available.

Another possible explanation for the relationships which emerged in this study may be the methodological contrast in factors describing stigmatized attitudes toward an individual (Jamie) and factors describing attitudes towards all people known to bear the given diagnosis label, in abstract. The measures for affective reaction and social distance were both framed to refer specifically to the individual described in the vignette, and participants were directed to describe their responses based on what they read. The measures for stigmatized beliefs and perceived dangerousness, on the other hand, refer more generally to "people with mental illness" as a group or to "people with depression" as a group, depending on which vignette was viewed. It therefore may be expected that the individual level factors would correlate, as would the group level factors. The participants would have similar responses on measures which are alike in that they both refer uniquely to Jamie, and indeed the results did show that social distance and affective reactions were significantly related. Similarly, participants would be expected to share similar responses on measures referring to an abstract group bearing the diagnosis label, and indeed the results did show that stigmatized beliefs and perceived dangerousness were significantly related.

The results of the regression in Table 4 implied that stigmatized beliefs about mental illness go hand in hand with perception of a suffering individual to be dangerous, regardless of the label. Not only that, but a weaker relationship was shown between past experience with a friend or co-worker suffering mental illness and perceived dangerousness, as well as between social distance and perceived dangerousness. These 
correlations of stigmatized factors prove to be an interesting aspect of the nature of stigmatization. While diagnosis labelling may only directly result in greater perceived dangerousness, perceived dangerousness is often well connected with other aspects of stigmatization discussed in past research. The results of this study did not show a relationship between existing family relationships or existing friendly or professional relationships with someone who had experienced mental illness either to affective reactions, or to stigmatized beliefs (RQ1, RQ2, RQ3, and RQ4). This contradicts past research, which showed that existing past relationships with family or friends and coworkers suffering from mental illness may reduce the effects of stigmatization after viewing a mental illness vignette. Indeed, whether or not past relationships with mentally ill people exist, the measures used for affective reaction and stigmatized beliefs nonetheless showed no change as indicators of stigmatization in the context of diagnosis labelling and social identity and were consistently overshadowed by the measure of perceived dangerousness.

The analysis of correlations in Table 1 revealed several additional interesting insights. First, although social desirability was not significantly related to perceived dangerousness of people with mental illness, the only factor which was related to the experimental manipulation, social desirability did have a significant negative relationship to affective reactions in response to the vignette. This is especially revealing given that more negative affective reactions to the vignette were later shown to be related to high desire for social distance in Table 2. The nature of the mutual relationships between affective reactions to mental illness, social desirability, and desire for social distance is a promising direction for future research. 
Given that perceived dangerousness was the only variable significantly related to the experimental manipulation, a series of four additional $t$-tests were conducted to check if the existence of a family relationship or of a friendly, co-worker, or neighbor relationship with someone who had experienced mental illness were related to perceived dangerousness of the character depicted. These were conducted post hoc in addition to the tests using affective reactions and stigmatized beliefs as dependent variables, as identified in the RQs prior to analysis and data gathering. Therefore, the results of these tests are purely tentative and exploratory in nature. Results showed, as expected, that there was consistently a significant relationship between whether participants had a friend or co-worker who had experienced mental illness, and the perceived dangerousness by those participants of people with mental illness. Furthermore, when participants reporting high social desirability were included, those who had a family relationship with someone experiencing mental illness were shown to perceive the character as more dangerous than the sample which did not include participants with the highest social desirability. This observation hints at the possibility that greater stigmatization might otherwise not have occurred, due to the closeness of the family relationship, if it weren't for the influence of those participants ranking highly in social desirability, a possibility which merits further research.

This observation could entail that people who tend to report what they believe is societally expected of them may be the most likely to experience powerful negative emotions in response to people bearing the stigmatizing mark of a diagnosis label, prior to drawing any other conclusion about them. Perceived dangerousness, however, otherwise the most telling factor of stigmatization shown in this study and the only factor 
significantly related to the experimental manipulation, was not significantly related to social desirability. This may mean that social desirability does not play a role in cognitive, post-affective stigmatized attributions on the level of social identity and labeling as strongly as it plays a role on the emotional and affective level... the gut level, so to speak. Indeed, people who reported high social desirability scores may not cognitively be aware that their pre-rational emotions are affecting the gut judgements they make about others.

A possible explanation may be that people who report high social desirability are more emotionally invested in projecting a positive image and identity, and therefore less likely to react with understanding when faced with less socially desirable interpersonal cues telling of a mentally ill individual. It follows that people who reported lower scores on the social desirability scale may be less prone to stereotypical attitudes such as perceived dangerousness, and to stigmatized attitudes taken as a whole. And while social distance was not significantly related to the experimental manipulation, as shown in H1, the variable did correlate significantly with every other variable included, with the exception of social desirability. Therefore, negative emotions likely trigger a desire for greater social distance, and this occurs simultaneously to the desire to avoid interactions perceived dangerous and which pose a threat to one's high social desirability. This is likely the cause for distancing, prejudice, and discrimination, especially among those who highly value their positive social identity.

\section{Limitations}

This study reveals that prior findings emphasizing social distance and affective reaction as crucial factors of stigmatization may not be relevant to the context of specific 
vs. non-specific labelling, as predicted. The results of the study may be limited in generalizability due to the limited undergraduate population sampled, and due to limitations inherent to the survey-based experimental design. Therefore, a more comprehensive interview-based course of research may reveal important insights on the social barriers and prototypes at play in perpetuating silence and preventing people with mental illness from seeking help. Greater nuance of the understandings and attributions elicited by the concepts of "depression" and "mental illness" may have been captured if the participants were allowed a wider opportunity to express their reactions and personal experiences, and to offer the reasons why they responded in the ways that they did. The questions used in this survey were limited to Likert scales validated in past research which, while proven statistically reliable, did not allow participants to elaborate a great deal of their own understanding of mental illness or stigmatization, with the exception of the final single open-ended question.

Secondly, the study may be limited in that, similarly to the experimental manipulation of vignettes, the content of survey questions themselves about stigmatized beliefs and perceived dangerousness were altered to use the term "mental illness" in place of the term "depression" for approximately half of the participants, matching the methodology used by Penn et al. (1994). This means that participants may have been responding to this variation when viewing the term in the survey questions, rather than responding solely to having viewed the term in the mental illness vignette, as intended. This detail of design was consistent with past research and was necessary, considering the way the survey prompts were phrased. Survey responses not only captured a variation in response to an otherwise identical initial stimulus, but also a variation which may have 
been triggered largely by this prompt late in the survey asking participants to give their own beliefs about two distinct labels

Finally, the study was limited in that perceived dangerousness was included in only one of the hypotheses and research questions posed in advance. Based on past research, perceived dangerousness was not expected to be the most significant factor predicted by the experimental manipulation, and therefore was not included in any research question and in only one hypothesis. Given the results of this study, future research should focus more exclusively and in greater detail on the constitutive aspects of this construct. The result may be characteristic of the nature of the modern conversation surrounding the term "mental illness", as school shootings and violence have been increasingly attributed in the national conversation to the mentally ill, or it may be the result of a changing popular conception of what "mental illness" means. Future research would benefit by expanding on the concept of perceived dangerousness, and further elaborating the connection between stigmatized perceptions of dangerousness and reluctance to seek treatment among sufferers of mental illness.

That being said, the results of this study provided a number of promising directions to pursue. Not only that, it clarifies the most urgent and powerful aspect of stigmatization, specifically, perceived dangerousness, by confirming the danger appraisal hypothesis found in past theory and providing substantial evidence for social stigmatization and stereotyping by participants in response to a mental illness vignette. These results have implications regarding the usefulness of using the term "mental illness" in campaigns to increase outreach to sufferers, and the prevalence of certain prototypical attributions related to the social identity of anyone bearing the non-specific 
label. Health professionals and communicators would benefit from addressing mental health concerns using specific diagnoses and the benefits of the treatments available for those diagnoses, and emphasizing the term "mental health", rather than confounding distinct challenges by including a disease like depression under the more stigmatized umbrella term "mental illness."

This conclusion may be practically applicable in future communication surrounding the issue of mental illness treatment and stigma reduction. For example, the USA Today in 2014 published a series of four feature stories by Rick Jervis, Kevin Johnson and Liz Szabo describing "A mental health system drowning from neglect" (Jervis, R., Johnson, K., \& Szabo, L., 2014). While hard-hitting, impressively comprehensive, and deeply revealing of a nationwide system desperately in need of greater funding and investment, the series consistently referred to patients as "the mentally ill" and included only a few anecdotes of successful treatment or the benefits of seeking help, which were then overshadowed by anecdotes of mental health patients attempting violent crime.

Mental illness was discussed for the most part without using reference to specific diagnoses and patients were positioned in the series either as victims or as a drain on society, unable to gain agency in their own recovery and more likely to leech off of public services or to cycle through the overcrowded prison system or become homeless. For example, the final paragraph of the first chapter in the series reads, "As they cycle between the street corner, jail cell, and hospital bed, the homeless who are mentally ill cost local, state, and federal agencies millions of dollars a year" (Jervis, R., et al., 2014). This kind of language lays the blame for 'wasted' resources and the 'cost to society' 
squarely on the shoulders of an objectified population who are in no way humanized or empowered to give back to a system unequipped to aid or rehabilitate them in the first place.

On the other hand, the series sheds light on a nation-wide crisis that otherwise may have been ignored or gone unreported. The multi-chapter series included feature stories on stigmatization, homelessness, imprisonment, and treatment, and includes anecdotes and multimedia to clearly illustrate the systemic and challenging nature of the mental health crisis. The series referred to stigmatization as "deeply embedded in American society" and, although it made the mistake of unfairly portraying mental health patients as inordinately criminal and violent, it succeeded in pointing out that avenues for treatment exist which simply have not been made widely available. By de-emphasizing dangerousness, focusing on successful methods of treatment, and using specific language to describe diagnoses and the benefits of treatment, a large-scale reporting project such as this one could more effectively aid in improving the system it seeks to reveal.

\section{Conclusion}

Mental illness remains a largely unspoken yet widespread public health epidemic faced by millions across the world, one which goes largely untreated even in the wealthiest countries. Although public consciousness of mental illness and awareness campaigns worldwide have increasingly caused the public to accept the symptoms of various diagnoses as biologically based and treatable with medication, and permanent institutionalization for those with mental illness and permanent damaging treatments like electroshock therapy have been steadily abandoned, the issue of mental illness remains shrouded in a cloud of silence and fear. Social and interpersonal stigmatization prevents 
people, whether recovering or afflicted, from feeling empowered to seek and maintain treatment and from achieving lasting mental health and normalcy.

This study confirmed that stigmatization in fact does exert a powerful influence on people's attitudes and opinions based simply on the use of the term "mental illness," compared to a specific diagnosis label such as "depression." Furthermore, this study showed that the primary set of stereotypes activated by the use of the "mental illness" label were those related to the dangerousness of the individual described. A person labelled and known by others to be "mentally ill" was considered to be more dangerous, although otherwise described in exactly the same manner as a person labelled and known to be "depressed." If a person labelled as "mentally ill" is considered less likely to be recommended for certain jobs, more likely to be avoided by neighbors, or less likely to be trusted with a hunting license or gun license, then patients have substantial rewards for concealing the existence of their illness and continuing to suffer in silence.

As it becomes more acceptable for people to discuss their experience of mental illness, to share their stories of treatment, and to impart to friends and communities that successful recovery is possible, the better become the chances that other sufferers will seek and maintain their own treatment and recovery. To achieve this goal, it is vitally important that stigmatization be named, understood, and actively combatted in public discourse. The results of this study call for further study and elaboration of the stigmatized belief that people with mental illness are likely to commit violent crimes, so that this stereotype can be counteracted intentionally. Health professionals and communicators should use sensitive and specific language when speaking about people 
with mental illness and maintain strong adherence to protecting patient privacy and information security, in order to prevent stereotyping and further identity damage.

By breaking down the barriers to treatment and increasing ease of access to mental health care and open communication on the topic, medical professionals and health communicators could create an easier world for the $50 \%$ or more of people who suffer from mental health challenges and do not receive treatment. This would mean more research to actively build a better understanding of stigmatization, a broader effort to avoid labels that perpetuate negative stereotypes, and establishment of more accessible and positive channels of outreach to this vulnerable population. With greater sensitivity and openness about mental health in our social relationships, many lives could be improved, and fewer people would continue to suffer. 


\section{References}

Ahmedani, B. K. (2011). Mental health stigma: Society, individuals, and the profession. Journal of Social Work Values and Ethics, 8(2), 1-16.

Angermeyer, M. C. \& Matschinger, H. (1997). Social distance towards the mentally ill: results of representative surveys in the Federal Republic of Germany. Psychological Medicine, 27, 131-141.

Angermeyer, M. C., Matschinger, H., \& Corrigan, P. (2004). Familiarity with mental illness and social distance from people with schizophrenia and major depression : testing a model using data from a representative population survey. Schizophrenia Research, 69, 175-182. doi: 10.1016/S0920-9964(03)00186-5

Barbour, J. B., Doshi, M. J., \& Hernandez, L. H. (2015). Telling global public health stories: Narrative message design for issues management. Communication Research, 43(6), 810-843. doi: 10.1177/0093650215579224

Barney, L. J., Griffiths, K. M., Jorm, A. F., \& Christensen, H. (2016). Stigma about depression and its impact on help-seeking intentions. Australian \& New Zealand Journal of Psychiatry, (40)1, 51-54. doi: 10.1080/j.1440-1614.2006.01741.x

Bogart, K. R., Rosa, N. M., \& Slepian, M. L. (2018). Born that way or became that way: Stigma toward congenital versus acquired disability. Group Processes \& Intergroup Relations, 1-19. Advanced online publication. doi: $10.1177 / 1368430218757897$

Chung, A. H., \& Slater, M. D. (2013). Reducing stigma and out-group distinctions through perspective-taking in narratives. Journal of Communication, 63(5), 894911. doi: 10.1111/jcom. 12050 
Clement, S., Schauman, O., Graham, T., Maggioni, F., Evans-Lacko, S., Bezberodovs, N., Morgan, C., Rusch, N., Brown, J. S. L., \& Thornicroft, G. (2015). What is the impact of mental-health-related stigma on help-seeking? A systematic review of quantitative and qualitative studies. Psychological Medicine, 45, 11-27. doi: $10.1017 / \mathrm{S} 0033291714000129$

Corrigan, P. (2004). How stigma interferes with mental health care. American Psychologist, 59(7), 614-625. doi: 10.1037/0003-066X.59.7.614

Corrigan, P. \& Watson, A. (2002). The paradox of self-stigma and mental illness. Clinical Psychology: Science and Practice, 9, 35-53. doi:10.1093/clipsy.9.1.35

Corrigan, P., Markowitz, F., Watson, A., Rowan, D., \& Kubiak, M. (2003). An attribution model of public discrimination towards persons with mental illness. Journal of Health and Social Behavior, 44(2), 162-179. Retrieved from http://www.jstor.org/stable/1519806

Fagley, N.S., Coleman, J. G., \& Simon, A. F. (2010). Effects of framing, perspective taking, and perspective (affective focus) on choice. Personality \& Individual Differences, 48(3), 264-269. doi: 10.1016/j.paid.2009.10.008

Frank, L. B., Murphy, S. T., Chatterjee, J. S., Moran, M. B., \& Baezconde-Garbanati, L. (2015). Telling stories, saving lives: Creating narrative health messages. Health Communication, 30(2), 154-163. doi: 10.1080/10410236.2014.974126

Gollust, S.E. \& Lynch, J. (2011). Who deserves health care? The effects of causal attributions and group cues on public attitudes about responsibility for health care costs. Journal of Health Politics, Policy, \& Law, 36(6), 1061-1095. doi: $10.1215 / 03616878-1460578$ 
Goffman, E. (1963). Stigma: Notes on the management of spoiled identity. Prentice-Hall: Englewood Cliffs, NJ.

Hogg, M. A. and Reid, S. A. (2006). Social identity, self-categorization, and the communication of group norms. Communication Theory, 16, 7-30. doi:10.1111/j.1468-2885.2006.00003.x

Jervis, R., Johnson, K., \& Szabo, L. (2014, May 12). The cost of not caring: Nowhere to go. USA Today. Retrieved from https://www.usatoday.com/story/news/nation/2014/05/12/mental-health-systemcrisis/7746535/

Kim, H. K. (2016). Efficacy of value-expressive messages at improving attitudes toward psychiatric help seeking for depression treatment among young adults. Journal of Communication in Healthcare, 9(4), 288-297. doi:

$10.1080 / 17538068.2016 .1248589$

King, M. \& Bruner, G. (2000). Social desirability bias: A neglected aspect of validity testing. Psychology and Marketing, 17(2), 79-103.

Kvaale, E. P., Gottdiener, W. H., Haslam, N. (2013). Biogenetic explanations and stigma: A meta-analytic review of associations among lay-people. Social Science and Medicine, 96(2013), 95-103.

Link, B., \& Phelan, J. (2001). Conceptualizing stigma. Annual Review of Sociology, 27, 363- 385. doi:https://doi.org/10.1146/annurev.soc.27.1.363

Link, B., Mirotznik, J., \& Cullen, F. (1991). The Effectiveness of Stigma Coping Orientations: Can Negative Consequences of Mental Illness Labeling Be Avoided? Journal of Health and Social Behavior, 32(3), 302-320. 
Link, B., Yang, L. H., Phelan, J. C., \& Collins, P.Y. (2004). Measuring mental illness stigma. Schizophrenia Bulletin, 30(3), 511-541.

Martiny, S. E., \& Kessler, T. (2014). Managing one’s social identity: Successful and unsuccessful identity management. European Journal of Social Psychology, 44, 748-757. doi: 10.1002/ejsp.2056

McGinty, E., Goldman, H. H., Pescosolido, B., \& Barry, C. L. (2014). Portraying mental illness and drug addiction as treatable health conditions: Effects of a randomized experiment on stigma and discrimination. Social Science \& Medicine, 126, 73-85. doi: 10.1016/j.socscimed.2014.12.010

Monroe, S. M., \& Harkness, K. L. (2012). Is depression a chronic mental illness? Psychological Medicine, 42, 899-902. doi: 10.1017/S0033291711002066 National Institute of Mental Health. (2017). Key substance use and mental health indicators in the United States: Results from the 2016 National Survey on Drug Use and Health (HHS Publication No. SMA 17-5044, NSDUH Series H52). Rockville, MD: Center for Behavioral Health Statistics and Quality, Substance Abuse and Mental Health Services Administration. Retrieved from https://www.samhsa.gov/data/

Norman, R. G., Sorrentino, R. M., Windell, D., \& Manchanda, R. (2008). The role of perceived norms in the stigmatization of mental illness. Social Psychiatry \& Psychiatric Epidemiology, 43(11), 851-859. doi: 10.1007/s00127-008-0375-4

Patel, V., \& Prince, M. (2010) Global Mental Health: A New Global Health Field Comes of Age. Journal of the American Medical Association, 303(19). 
Penn, D., Guynan, K., Daily, T., Spaulding, W. D., Garbin, C. P., \& Sullivan, M. (1994). Dispelling the stigma of schizophrenia: What kind of information is best? Schizophrenia Bulletin, 20(3), 567-578. doi: 10.1093/schbul/20.3.567

Perkins, R., \& Repper, J. (2013). Prejudice, discrimination and social exclusion: reducing the barriers to recovery for people diagnosed with mental health problems in the UK. Neuropsychiatry, 3(4), 377+. doi: 10.2217/npy.13.34

Pescosolido, B. et al. (2010). “A disease like any other?” A decade of change in public reactions to schizophrenia, depression, and alcohol dependence. The American Journal of Psychiatry, 167(11), 1321-1330. doi: 10.1176/appi.ajp.2010.09121743

Phelan, J., \& Basow, S. (2007). College students' attitudes toward mental illness: An examination of the stigma process. Journal of Applied Social Psychology, 37(12), 2877-2902.

Prins, M. A., Verhaak, P. F. M., Bensing, J. M., \& van der Meer, K. (2008). Health Beliefs and perceived need for mental health care of anxiety and depressionThe patients' perspective explored. Clinical Psychology Review, 28, 1038-1058. doi: 10.1016/j.cpr.2008.02.009

Reynolds, W. (1982). Development of reliable and valid short forms of the MarloweCrowne social desirability scale. Journal of Clinical Psychology, 38(1), 119-125. doi: 10.1002/1097-4679(198201)38:1

Ridge, D. (2012) Use of patient narratives in promoting recovery from depression. Nursing Standard, 26(47), 35-40.

Scheff, T. J. (1966). Being Mentally Ill. Chicago: Aldine Publishing Company. 
Silk, K. J., Perrault, E. K., Nazione, S. A., Pace, K., \& Collins Eaglin, J. (2017) Evaluation of a Social Norms Approach to a Suicide Prevention Campaign. Journal of Health Communication, (22)2, 135-142.

Smeekes, A., \& Verkuyten, M. (2013). Collective self-continuity, group identification and in-group defense. Journal of Experimental Social Psychology, (49)6, 984994. doi: 10.1016/j.jesp.2013.06.004

Stout, P. A., Villegas, J., Jennings, N. A. (2004). Images of mental illness in the media: Identifying gaps in the research. Schizophrenia Bulletin, (30)3, 543-561.

Ware, N. C., Hopper, K., Tugenberg, T., Dickey, B., \& Fisher, D. (2007). Connectedness and citizenship: Redefining social integration. Psychiatric Services, (58)4, 469474.

Webb, M., Peterson, J., Willis, S. C., Rodney, H., Siebert, E., Carlile, J. A., Stinar, L. (2016). The role of empathy and adult attachment in predicting stigma toward severe and persistent mental illness and other psychosocial or health conditions. Journal of Mental Health Counseling, 38(1), 62-78. doi: 10.17744/mehc.38.1.05

Wright, A., Jorm, A. F. Mackinnon, A. J. (2011). Labeling of mental disorders and stigma in young people. Social Science and Medicine, 73(4), 498-506. doi: 10.1016/j.socscimed.2011.06.015

Yeh, M., Jewell, R., \& Thomas, V. (2017). The Stigma of Mental Illness: Using Segmentation for Social Change. Journal of Public Policy \& Marketing, 36(1), $97-116$. 


\section{Appendix A Informed Consent Form}

\section{Informed Consent}

You are invited to participate in a research study conducted by Justin Leverett under the direction of Dr. Frank. This study attempts to collect information about your views on mental health communication. This study will not ask personal questions about your own mental health. You were selected as a possible participant in this study because you are enrolled as an undergraduate in a communication course.

\section{Procedures}

If you decide to participate, you will be asked to complete the following questionnaire. The questionnaire will take approximately 15 minutes or less.

\section{Risks/Discomforts}

Risks are minimal for involvement in this study. However, you may feel uncomfortable when asked to share information about your views on mental health. You are welcome to skip any question that you feel uncomfortable answering.

\section{Benefits}

You may not receive any direct benefit from taking part in this study. However, it is hoped that through your participation, the study may help to increase knowledge which may help others in the future.

\section{Confidentiality}

All information that is obtained in connection with this study will be kept confidential and will only be reported in an aggregate format (by reporting only combined results and never reporting individual ones). All questionnaires will be concealed, and no one other than the research team will have access to them. At no point will you name be linked to your answers.

\section{Compensation}

You may earn academic extra credit for your participation. Follow the directions at the end of the survey to print and turn your survey completion form in to the pink drop box in the Communication Department offices, UCB 440. Your form will not be linked to your survey responses. Your name is collected only so that your professor may give you extra credit for your class project. 


\section{Participation}

Participation in this research study is completely voluntary. You have the right to withdraw at any time or refuse to participate entirely, and it will not affect your course grade in the class or standing with the university. If you wish to receive extra credit but do not wish to complete the survey, contact the researcher for an alternative extra credit opportunity.

\section{Questions about the Research}

If you have questions or concerns regarding this study, contact Justin Leverett at js15@pdx.edu or Dr. Frank at1frank@pdx.edu.

\section{Questions about your Rights as Research Participants}

If you have questions or concerns about your rights as a research subject, please contact the PSU Office of Research Integrity, 1600 SW 4th Ave., Market Center Building, Ste. 620, Portland State University, 503-725-2227.

By completing this survey, you are certifying that you are 18 years of age or older, that you have read and understood the above information and agree to take part in the survey. To print this consent form on a PC, press CTRL $+\mathrm{P}$. To print this consent form on a Mac, press COMMAND $+\mathrm{P}$.

If at this point you choose to continue in this research study, please click ">>>" to continue. 


\section{Appendix B \\ Recruitment Script}

[To be read aloud to the class when asking for participants]

Thank you for allowing me time to present you with this opportunity. I am conducting a research study on your views about mental health communication.

Participants in this study should be 18 years of age or older. Participation in this study is completely voluntary and your responses will remain confidential. Choosing to participate or choosing to not participate will NOT negatively impact your course grade in any way. If you choose to participate in this study, you will complete a questionnaire in exchange for extra credit in this course. The survey should take approximately 15 minutes.

If you 1) choose not to participate in this survey, 2) decide to withdraw early, or 3) have already taken this survey for extra credit in another course, you will have the option to complete an alternate extra credit assignment, and should contact me. This survey is also being offered in [INCLUDE A LIST OF OTHER CLASSES AND PROFESSOR NAMES]. You may only take the survey once for extra credit. However, you are able to receive extra credit in each class. Please email me for information on the alternative opportunities for extra credit.

If you would like to participate in this study, please click on the survey link on D2L. You can take this survey at any computer with internet access and a printer.

When the survey is complete, you will need to print a completion form, and write in your first name, last name, course name, and instructor in order to receive the extra credit. Your name will only be used for extra credit purposes and will not be tied to your responses.

The survey must be completed and the final completion form printed and turned in to the box labeled "Survey Drop Box" in the Communication Department (UCB 440) by [DATE TBD], 2018 at 5:00 p.m.

If you have any questions, feel free to contact the researcher Justin Leverett.

Thank you for your time. Your participation is greatly appreciated. 


\section{Appendix C \\ Stigmatization of Mental Illness Survey Instrument \\ Informed Consent}

You are invited to participate in a research study conducted by Justin Leverett under the direction of Dr. Frank. This study attempts to collect information about your views on mental health communication. This study will not ask personal questions about your own mental health. You were selected as a possible participant in this study because you are enrolled as an undergraduate in a communication course.

\section{Procedures}

If you decide to participate, you will be asked to complete the following questionnaire. The questionnaire will take approximately 15 minutes or less.

\section{Risks/Discomforts}

Risks are minimal for involvement in this study. However, you may feel uncomfortable when asked to share information about your views on mental health. You are welcome to skip any question that you feel uncomfortable answering.

\section{Benefits}

You may not receive any direct benefit from taking part in this study. However, it is hoped that through your participation, the study may help to increase knowledge which may help others in the future.

\section{Confidentiality}

All information that is obtained in connection with this study will be kept confidential and will only be reported in an aggregate format (by reporting only combined results and never reporting individual ones). All questionnaires will be concealed, and no one other than the research team will have access to them. At no point will you name be linked to your answers.

\section{Compensation}

You may earn academic extra credit for your participation. Follow the directions at the end of the survey to print and turn your survey completion form in to the pink drop box in the Communication Department offices, UCB 440. Your form will not be linked to your survey responses. Your name is collected only so that your professor may give you extra credit for your class project. 


\section{Participation}

Participation in this research study is completely voluntary. You have the right to withdraw at any time or refuse to participate entirely, and it will not affect your course grade in the class or standing with the university. If you wish to receive extra credit but do not wish to complete the survey, contact the researcher for an alternative extra credit opportunity.

\section{Questions about the Research}

If you have questions or concerns regarding this study, contact Justin Leverett at js15@pdx.edu or Dr. Frank at 1frank@pdx.edu.

\section{Questions about your Rights as Research Participants}

If you have questions or concerns about your rights as a research subject, please contact the PSU Office of Research Integrity, 1600 SW 4th Ave., Market Center Building, Ste. 620, Portland State University, 503-725-2227.

By completing this survey, you are certifying that you are 18 years of age or older, that you have read and understood the above information and agree to take part in the survey. To print this consent form on a PC, press CTRL $+\mathrm{P}$. To print this consent form on a Mac, press COMMAND $+\mathrm{P}$.

If at this point you choose to continue in this research study, please click ">>>" to continue.

\section{Start of Block: Block 2}

Q6 Imagine that you know the following about a friend, Jamie, with whom you occasionally spend time.

Your friend seems depressed. Unlike before, Jamie is down and sad without being able to give a reason for his feeling low. He appears serious and worried. There is no longer anything that will make him laugh. Jamie hardly ever talks now, and if he says something, he speaks in a low tone of voice about the worries he has with regard to the future. He feels useless and has the impression that he does everything wrong. All attempts to cheer Jamie up have failed. He lost all interest in things and is not motivated to do anything. He complains often of waking up in the middle of the night and not being able to get back to sleep. By the morning, he feels exhausted and without energy. He says that he encounters difficulty in concentrating on his job. Unlike before, everything takes 
him a long time to do. He hardly manages his workload. As a consequence, Jamie has been summoned to his boss.

Jamie is suffering from depression.

\section{End of Block: Block 2}

\section{Start of Block: Block 3}

Q7 Imagine that you know the following about a friend, Jamie, with whom you occasionally spend time.

Your friend seems mentally ill. Unlike before, Jamie is down and sad without being able to give a reason for his feeling low. He appears serious and worried. There is no longer anything that will make him laugh. Jamie hardly ever talks, and if he says something, he speaks in a low tone of voice about the worries he has with regard to the future. He feels useless and has the impression that he does everything wrong. All attempts to cheer Jamie up have failed. He lost all interest in things and is not motivated to do anything. $\mathrm{He}$ complains often of waking up in the middle of the night and not being able to get back to sleep. By the morning, he feels exhausted and without energy. He says that he encounters difficulty in concentrating on his job. Unlike before, everything takes him a long time to do. He hardly manages his workload. As a consequence, Jamie has been summoned to his boss.

Jamie is suffering from a mental illness.

\section{End of Block: Block 3}

\section{Start of Block: Block 5}

Q9 Based on the description you just read, rate the following statements on the following scale:

\begin{tabular}{c|ccccc} 
& $\begin{array}{c}\text { Definitely } \\
\text { willing }\end{array}$ & $\begin{array}{c}\text { Probably } \\
\text { willing }\end{array}$ & $\begin{array}{c}\text { Not } \\
\text { sure }\end{array}$ & $\begin{array}{c}\text { Probably } \\
\text { unwilling }\end{array}$ & $\begin{array}{c}\text { Definitely } \\
\text { unwilling }\end{array}$ \\
\hline $\begin{array}{c}\text { How would you feel } \\
\text { about being a } \\
\text { roommate with } \\
\text { someone like Jamie? }\end{array}$ & & & & & \\
& & & & & \\
\end{tabular}


How would you feel about being a coworker in the same job as someone like Jamie?

How would you feel about having someone like Jamie as a neighbor?

How would you feel about Jamie as the caretaker of your children for a couple of hours?

How would you feel about having your children marry someone like Jamie?

How would you feel about introducing Jamie to a single person you are friendly with?

How would you feel about recommending someone like Jamie for a job working for a friend of yours?

a

\section{End of Block: Block 5}

\section{Start of Block: Block 6}

Q16 If you were to interact with Jamie, please indicate how you would feel about the interaction, based on the vignette.

Each question below has a pair of opposite impressions or emotions (such as "optimistic" vs. "pessimistic"). Please mark one of the six locations, on the scale, closest to the term that you feel most closely matches the impression or emotion you'd experience in this 
interaction. For example, if you'd feel very optimistic about interacting with Jamie, please select a position on the scale very close to the term "optimistic." Please make your decisions quickly, based on your truest and most authentic gut feeling.

\begin{tabular}{|c|c|c|c|c|c|c|c|}
\hline & $1(1)$ & $2(2)$ & $3(3)$ & $4(4)$ & $5(5)$ & $6(6)$ & \\
\hline Pessimistic & & & & & & & Optimistic \\
\hline Tranquil & & & & & & & Anxious \\
\hline Supportive & & & & & & & Resentful \\
\hline Fearful & & & & & & & Confident \\
\hline Empathic & & & & & & & Angry \\
\hline Disgusted & & & & & & & Sympathetic \\
\hline Apprehensive & & & & & & & Comfortable \\
\hline Irritable & & & & & & & Patient \\
\hline Relaxed & & & & & & & Tense \\
\hline Calm & & & & & & & Nervous \\
\hline
\end{tabular}


Q18 Please indicate your reaction to the following statements regarding mental illness [depression depending on experimental condition]:

\begin{tabular}{|c|c|c|c|c|c|c|}
\hline & $\begin{array}{l}\text { Strongly } \\
\text { Disagree }\end{array}$ & Disagree & $\begin{array}{c}\text { Somewhat } \\
\text { Disagree }\end{array}$ & $\begin{array}{c}\text { Somewhat } \\
\text { Agree }\end{array}$ & Agree & $\begin{array}{c}\text { Strongly } \\
\text { Agree }\end{array}$ \\
\hline $\begin{array}{l}\text { Whether or not } \\
\text { you get a mental } \\
\text { illness is a matter } \\
\text { of will power and } \\
\text { self discipline }\end{array}$ & & & & & & \\
\hline $\begin{array}{l}\text { Mental illness } \\
\text { comes about } \\
\text { when someone } \\
\text { stops making an } \\
\text { effort to deal with } \\
\text { the challenges of } \\
\text { life }\end{array}$ & & & & & & \\
\hline $\begin{array}{l}\text { People develop } \\
\text { mental illness } \\
\text { because they are } \\
\text { easily stressed }\end{array}$ & & & & & & \\
\hline $\begin{array}{l}\text { Mental illness } \\
\text { results from a } \\
\text { failure of self } \\
\text { control }\end{array}$ & & & & & & \\
\hline $\begin{array}{l}\text { Most of us from } \\
\text { time to time show } \\
\text { symptoms of } \\
\text { mental illness }\end{array}$ & & & & & & \\
\hline $\begin{array}{l}\text { Normal people } \\
\text { can have some of } \\
\text { the symptoms of } \\
\text { mental illness }\end{array}$ & & & & & & \\
\hline $\begin{array}{l}\text { Given extreme } \\
\text { circumstances, } \\
\text { many of us could } \\
\text { show signs of } \\
\text { mental illness }\end{array}$ & & $\cap$ & & & & \\
\hline
\end{tabular}




People with
mental illness
often say rude
and upsetting
things
You can often be
embarrassed by
what someone
with mental
illness says or
does
People with
mental illness are
often
inappropriate
when interacting
with others

End of Block: Block 7

Start of Block: Block 8

Q17 Please indicate your reaction to the following statements about people with mental illness [depression depending on experimental condition]:

\begin{tabular}{|c|c|c|c|c|c|c|}
\hline & $\begin{array}{l}\text { Strongly } \\
\text { Disagree }\end{array}$ & Disagree & $\begin{array}{l}\text { Somewhat } \\
\text { Disagree }\end{array}$ & $\begin{array}{c}\text { Somewhat } \\
\text { Agree }\end{array}$ & Agree & $\begin{array}{c}\text { Strongly } \\
\text { Agree }\end{array}$ \\
\hline $\begin{array}{l}\text { If a group of } \\
\text { people with } \\
\text { mental illness } \\
\text { lived nearby, I } \\
\text { would not allow } \\
\text { my children to } \\
\text { go to the movie } \\
\text { theater alone. }\end{array}$ & & & & & & C \\
\hline $\begin{array}{l}\text { If someone with } \\
\text { mental illness } \\
\text { applied for a } \\
\text { teaching }\end{array}$ & & & & & & $\Omega$ \\
\hline
\end{tabular}


position at a

grade school

and was

qualified for the

job, I would

recommend

hiring him/her.

One important thing about

people with

mental illness is that you cannot tell what they will do from

one minute to the next.

If I know a person has been diagnosed with a mental illness, I will be less likely to trust them.

The main purpose of mental hospitals should be to protect people from mentally ill people.

If someone with a mental illness lived nearby, I would not hesitate to allow young children under my care on the sidewalk.

Although some people with 


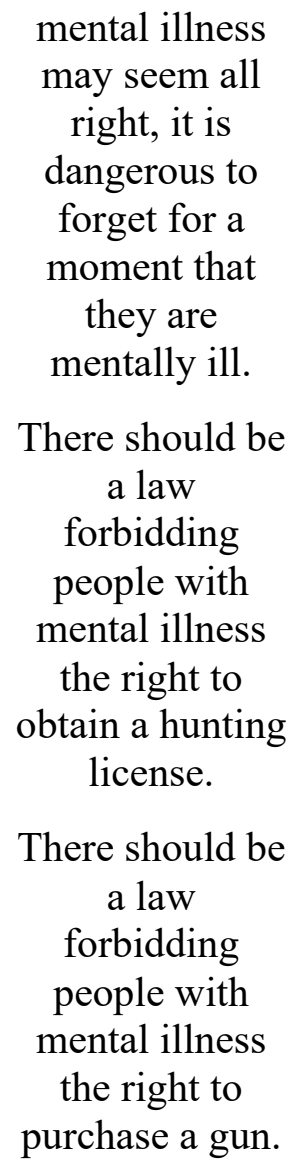

There should be

a law

forbidding people with mental illness the right to obtain a hunting license.

There should be a law forbidding people with mental illness the right to purchase a gun.

\section{End of Block: Block 8}

\section{Start of Block: Block 9}

Q13 Please indicate your reaction to the following statements:

\begin{tabular}{|c|c|c|c|c|c|c|}
\hline & $\begin{array}{l}\text { Strongly } \\
\text { Disagree }\end{array}$ & Disagree & $\begin{array}{l}\text { Somewhat } \\
\text { Disagree }\end{array}$ & $\begin{array}{c}\text { Somewhat } \\
\text { Agree }\end{array}$ & Agree & $\begin{array}{c}\text { Strongly } \\
\text { Agree }\end{array}$ \\
\hline $\begin{array}{l}\text { It is sometimes } \\
\text { hard to go on with } \\
\text { my work when I } \\
\text { am not } \\
\text { encouraged. }\end{array}$ & & & & & & \\
\hline $\begin{array}{l}\text { I sometimes feel } \\
\text { resentful when I } \\
\text { don't get my way. }\end{array}$ & & & & & & \\
\hline
\end{tabular}




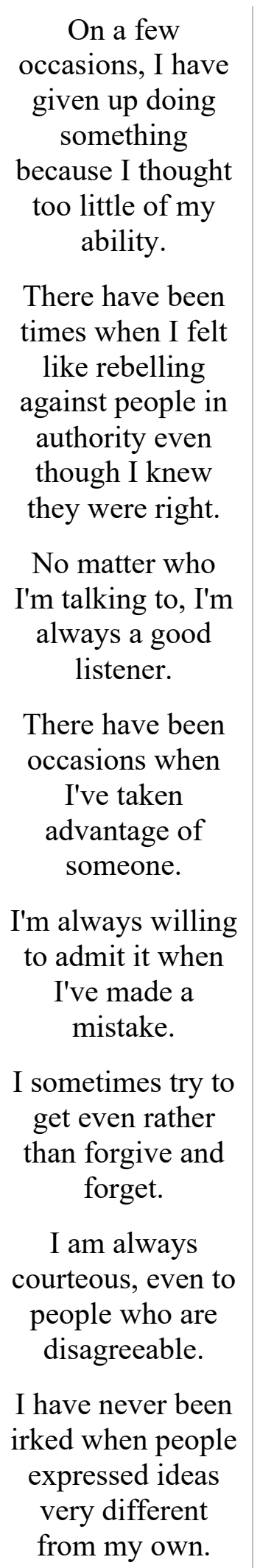


There have been times when I was quite jealous of the good fortunes of others.

I am sometimes irritated by people who ask favors of me.

I have never deliberately said something that hurt someone's feelings.

\section{End of Block: Block 9}

\section{Start of Block: Manipulation Check}

Q20 Which of the following statements best applies to your friend Jamie?

Jamie is experiencing nothing abnormal (1)

Jamie is experiencing depression (2)

Jamie is experiencing a mental illness (3)

I prefer not to answer (4) 
Q25 To what degree do you consider depression to be a form of mental illness?

\begin{tabular}{c|cccccc} 
& $\begin{array}{c}\text { Strongly } \\
\text { disagree }\end{array}$ & Disagree & $\begin{array}{c}\text { Somewhat } \\
\text { disagree }\end{array}$ & $\begin{array}{c}\text { Somewhat } \\
\text { Agree }\end{array}$ & Agree & $\begin{array}{c}\text { Strongly } \\
\text { Agree }\end{array}$ \\
\hline $\begin{array}{c}\text { I consider } \\
\text { depression } \\
\text { to be a form } \\
\text { of mental } \\
\text { illness }\end{array}$ & 0 & 0 & & & \\
\end{tabular}

\section{End of Block: Manipulation Check}

Start of Block: Demographics

Q1 What is your gender?

Male (1)

Female (2)

Other (3)

Q4 What year were you born?

จ 2000 (1) ... 1918 (83) 
Q21 Please identify your ethnicity

Asian/Pacific Islander (1)

Black or African American (2)

Hispanic or Latino (3)

White/Caucasian (4)

Other (5)

Q2 Do you have a family member who has been or is undergoing psychiatric treatment?
Yes (1)
No (2)
I prefer not to answer (3)

Q24 Do you know someone within your circle of friends, among your co-workers, or in your neighborhood who has been or is undergoing psychiatric treatment?

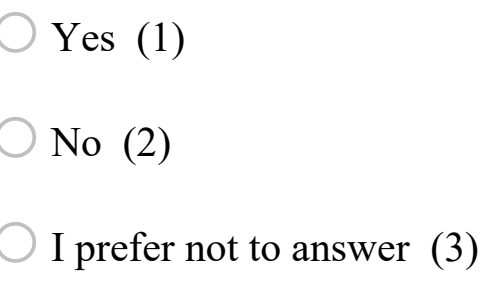

Q22 Do you have any additional thoughts or reactions you would like to share? 


\section{End of Block: Demographics}

\section{Start of Block: Block 11}

Q16 Thank You

\section{Extra Credit Survey - Mental Health Communication}

You have completed this survey. Thank you for your time. To receive extra credit for your class, please print and complete this page legibly.

Name

Course

Instructor

Bring this page to UCB 440, and place it in the box labeled "Survey Drop Box." If you have any questions about this survey or receiving extra credit, please email Justin Leverett at js15@pdx.edu or Dr. Lauren Frank at lfrank@pdx.edu. 